\title{
The influence of probabilistic volcanic hazard map properties on hazard communication
}

\author{
Mary Anne Thompson*, Jan M Lindsay and JC Gaillard
}

\begin{abstract}
Probabilistic volcanic hazard analysis is becoming an increasingly popular component of volcanic risk reduction strategies worldwide. While probabilistic hazard analyses offer many advantages for decision-making, displaying the statistical results of these analyses on a map presents new hazard communication challenges. Probabilistic information is complex, difficult to interpret, and associated with uncertainties. Conveying such complicated data on a static map image without careful consideration of user perspectives or context, may result in contrasting interpretations, misunderstandings, or aversion to using the map. Here, we present the results of interviews and surveys conducted with organisational stakeholders and scientists in New Zealand which explored how probabilistic volcanic hazard map properties influence map interpretation, understanding, and preference. Our results suggest that data classification, colour scheme, content, and key expression play important roles in how users engage with and interpret probabilistic volcanic hazard maps.

Data classification was found to influence the participants' perceived uncertainty and data reading accuracy, with isarithmic style maps reducing uncertainty and increasing accuracy best. Colour scheme had a strong influence on the type of hazard messages interpreted, with a red-yellow scheme conveying the message of a hazard distribution (high to low), and a red-yellow-blue scheme conveying the message of hazard state (present or absent) and/or risk. Multiple types of map content were found to be useful, and hazard curves were viewed as valuable supplements. The concept of "confidence" was more easily interpreted than upper and lower percentiles when expressing uncertainty on the hazard curves. Numerical and verbal expression in the key also had an influence on interpretation, with a combination of both a percent (e.g., 25\%) and a natural frequency (e.g., 1 in 4) "probability" being the most inclusive and widely-understood expression. The importance of these map property choices was underscored by a high portion of participants preferring to receive maps in unalterable formats, such as PDF.

This study illustrates how engaging with users in a bottom-up approach can complement and enhance top-down approaches to volcanic hazard mapping through a collaborative and integrative design process which may help to prevent miscommunications in a future crisis when maps are likely to be drafted and disseminated rapidly.
\end{abstract}

Keywords: Hazard communication; Hazard maps; Probabilistic volcanic hazard analysis; Hazard curve; Interviews; Surveys; Stakeholders

\section{Introduction}

Volcanic hazards are spatial phenomena, described and communicated globally using maps. In conventional hazard mapping practice, scientists analyse data about volcanic hazards, and then display the results on a map for a diverse audience of readers. However, this insular topdown approach to volcanic hazard communication does not necessarily translate into effective hazard awareness or informed decision-making, which are key contributors

\footnotetext{
* Correspondence: m.thompson@auckland.ac.nz

School of Environment, University of Auckland, Private Bag 92019, Auckland
} 1142, New Zealand to risk reduction. These factors are dependent on how the reader interprets and understands the hazard map, a facet of volcanic hazard communication that has been relatively unexplored.

Wide variation in data type, hazard modelling techniques, cartographic styles, and subjective preference has led to a vast diversity in the ways volcanic hazard information is represented on maps (Calder et al. 2012), yet limited attention has been paid to the impact of these choices on reader response and comprehension. For example, does the use of a particular colour scheme (e.g., blues versus reds), data classification (e.g., stretched versus binned),

\section{Springer}


or key expression (e.g., $10 \%$ versus 1 in 10) affect the way that a user interprets hazard information from the map? Geography (e.g., Robinson 1967; Bertin 1983; MacEachren 1995; Monmonier 1996; Kunz and Hurni 2011) and communication (e.g., Fisher 1991; Hoffrage et al. 2000; Severtson and Myers 2013; Doyle et al. 2014) research literature suggests that these types of properties may play an important role in hazard information processing. As capabilities and accessibility of hazard analyses continue to advance, it is important and timely to investigate how quantitative hazard map information is interpreted by those who may refer to the maps for decision-making. Initial interpretations of maps become particularly important in the context of decision-making during high-stakes, timepressure crisis situations when reliance on affective heuristics, or intuitive feelings about the map, is likely to be high (Finucane et al. 2000).

In this New Zealand-based study, we use qualitative and quantitative methodologies to empirically investigate how certain map properties affect the way that stakeholders and scientists respond to and interpret information from probabilistic-style volcanic hazard maps, and aim to gain key map user perspectives on these hazard map properties. Understanding how map properties influence map legibility and accessibility can help build awareness in the scientific community about the impact of certain choices when designing hazard maps, and accordingly, help improve the consistency, clarity, and effectiveness of volcanic hazard communication.

\section{Properties and users of probabilistic volcanic hazard maps}

Volcanic hazard maps are thematic maps, in which the features selected as primary map content are themed on information about the potential dangers associated with volcanoes. Probabilistic volcanic hazard maps depict, in varying ways, the likelihood of a certain dangerous volcanic phenomenon(a) occurring in a particular area in a specific time frame. Computational advances and development of a number of probabilistic volcanic hazard analysis methodologies over the past decade (e.g., Mader et al. 2006) have led to a marked increase in the amount of probabilistic volcanic hazard maps being created today. There are many advantages of using a probabilistic approach to analyse volcanic hazards. Volcanoes are inherently complex systems associated with many degrees of uncertainty. Probabilistic methods allow scientists to evaluate the unknowns and to quantify and compare the likelihood of a broad range of different possible hazard scenarios, introducing more practical applications to risk assessment than traditional methods which typically analyse only one scenario (Newhall and Hoblitt 2002; Marzocchi et al. 2012). However, using probabilistic volcanic hazard data to build hazard maps also presents new challenges. Probabilities are inherently difficult to communicate and understand among experts and non-experts alike (Hoffrage et al. 2000; Spiegelhalter et al. 2011), and are interpreted and contextualised differently by different types of map users (Reyna and Brainerd 2008; Doyle et al. 2014). Conveying uncertain data using concrete map images may also introduce communication obstacles (Severtson and Myers 2013).

Many methods exist for both generalising (simplifying) and representing (depicting) thematic content on maps (Slocum 1999; Dent et al. 2009). Extensive options mean that strikingly different maps can be created from a single set of data. Such choices for representing the data may have important impacts on how the map is perceived and interpreted (Monmonier 1996). While a map may be designed to convey a single dataset of interest, it does not convey a single universal message. Each user constructs their own individual knowledge from interpreting the different symbols, colours, and expressions on the map (Bertin 1983; MacEachren 1995). Some key thematic map properties for which it is important to consider the choice of representational style are: data classification, map content, and colour scheme (Monmonier 1996; Dent et al. 2009).

\section{Data classification}

Data classification refers to the characterisation and categorisation of a dataset into a particular visual symbology (Dent et al. 2009; Slocum 1999). For example, for a dataset which comprises 1,000 numerical values that range from 1 to 100 , e.g., probabilistic hazard values, those values can be stretched gradationally over a gradual ramp of colours, where each value responds to a unique shade of colour on the ramp (e.g., white $=0$ to black $=100$ for a greyscale ramp). Isopleths or isarithms (lines connecting points of equal value) can be applied on top of the shaded classification to provide points of reference for the reader. Alternatively, the numerical values can be classed into exclusive bins which contain a specific range of values (e.g., $1-9,10-19$, and $20-29$ ) and are represented by a unique colour. All values that fall together within a certain bin, or colour, are equally representative of that category. Applying different data classifications can yield markedly different patterns on the map, and can also influence how readers interpret the data (Robinson et al. 1995; Monmonier 1996; Brewer and Pickle 2002).

\section{Content}

Map content is another important property which can influence interpretation of thematic maps (Monmonier 1996; Dent et al. 2009). Background content, such as boundaries, rivers, and landforms, are provided as points of reference for the reader, and are essential for users to be able to orient themselves with the data. Haynes et al. 
(2007) and Nave et al. (2010) found that selection of background content can have a significant influence on how well readers understand volcanic hazard maps, particularly among local populations living proximal to the volcano. The representation of thematic feature content also has an impact on how readers interpret the map. Probabilistic hazard datasets are typically quite robust in that they often include a range of data types (e.g., volcanic ash thickness, ash grain size) at multiple levels of uncertainty (e.g., $90^{\text {th }}$ percentile, average) over a number of different time frames (e.g., in the event of an eruption, in the next 10 years). For example, some probabilistic volcanic hazard map toolsets are currently being designed to output two types of mappable content: a distribution of the probabilities of reaching and exceeding a fixed hazard intensity threshold (e.g., $10 \mathrm{~mm}$ of ash), or a distribution of hazard intensities expected at a fixed probability threshold (e.g., 25\%) over any user-defined timeframe (Tonini et al. in press). Certain types of hazard information may have different meanings and salience to different types of map users.

\section{Colour scheme}

Influencing more than just aesthetics, colour is a map property that has the power to provide visual contrast, unify elements, and guide attention of the map reader (Robinson 1967; Wolfe and Horowitz 2004). Blends of colour hue, saturation, and lightness can be manipulated to create a broad range of appropriate and logical colour schemes for maps. However, colour schemes also have a high margin for confusion (Brewer 1994; Robinson et al. 1995; Olson and Brewer 1997). Colours are inherently imbued with meanings for the map reader (Robinson 1967; Bertin 1983; Brewer 1994; Dent et al. 2009). While many volcanic hazard maps employ a Western greenyellow-red "stoplight" colour scheme, or a blue-yellowred "cold to hot" colour scheme, these may have unintended meanings for some map readers (Monmonier 1996). For example, red may be associated with "hot" or "bad" and green with "vegetation" or "good". A greenred diverging colour scheme is also likely to be very difficult to perceive for a colour blind user (Olson and Brewer 1997; Jenny and Kelso 2007; Brewer et al. 2013). Approximately $8 \%$ of males and $0.5 \%$ of females have some form of colour-vision deficiency (AOA 2014) and this can cause complications if not taken into consideration in map colour scheme design (Olson and Brewer 1997; Jenny and Kelso 2007). Although map makers strive for the highest degree of objectivity in designing probabilistic hazard maps, these fundamental choices for colour scheme, content type, and data classification are largely driven by subjective preference. Currently, there are few recommendations available for choosing appropriate styles, as the impact of these choices has not previously been tested with volcanic hazard map users.

\section{Map users}

Volcanic hazard maps have a wide range of applications and uses, and accordingly, they have many different types of users. In New Zealand, some important hazard map stakeholders are in local and regional government, health, education, agriculture, aviation, communications, emergency management, and in other groups which may use volcanic hazard information to make decisions regarding national, institutional, or local risk reduction. The detailed quantitative nature of probabilistic volcanic hazard information is well suited for organisational stakeholder decision-making, and could enhance the structure, performance, and reliability of decision-making strategies (Woo 2008, 2009; Marzocchi et al. 2012). Although each stakeholder will have different perspectives and informational needs, resource and time constraints make it impractical to develop unique hazard maps for each user group, particularly in a time of volcanic crisis (Leonard et al. 2014). It is therefore important to investigate how hazards maps can be designed to maintain a wide degree of relevance, legibility, and applicability among a diverse group of stakeholders. In order to do this, stakeholder perspectives and opinions must be taken into account, as studies show that differences exist in the way that scientists (typically the hazard map makers) and other stakeholders, such as emergency managers, understand and use probabilistic volcanic hazard information (Doyle et al. 2011, 2014). Emergency managers are a particularly important group of hazard map users in New Zealand, as they are responsible for managing many short- and long-term natural hazard and risk reduction decisions which directly affect populations at risk (MCDEM 2002).

We emphasise that people at risk are also very important stakeholders in probabilistic volcanic hazard maps and in the decisions made using such maps, but acknowledge that a survey of those at risk is outside of the scope of this study. We also acknowledge that the New Zealand stakeholder community is a generally well-educated populace, and typically has a good grasp of the concept of volcanic hazard due to regular engagement with the scientific community. Exploring probabilistic volcanic hazard map perception in other cultural, volcanic, and socio-economic settings both within New Zealand and internationally, is an important area for further research.

\section{Methods}

A pragmatic mixed-methods approach was adopted (Morgan 2007), where qualitative semi-structured inperson interviews were implemented as a pilot study to test ideas and questions which informed the development of a qualitative and quantitative online survey exploring 
the influence of probabilistic volcanic hazard map design properties on understanding and communicating hazard. Inductive thematic analysis of semi-structured interviews was used to identify themes regarding how scientists and stakeholders felt about certain map design properties and how they engaged with the hazard maps. Design properties which emerged as themes which have a sensitive or powerful impact on interpretation of the hazard maps were explored further in the survey among a broader sample group. Both methodological components of this study were individually approved by a human participation ethics committee.

It was emphasised to participants that the data on the maps were hypothetical, and all participants were reminded that the maps seen were not to be referred to for any type of decision-making. The datasets used were in raster format and represented the probability of accumulating a certain thickness of volcanic ash in the event of a rhyolitic eruption from Tarawera volcano in New Zealand's North Island. Datasets were based on actual ash hazard analyses done by Thompson et al. (under review). Tarawera volcano is a well-known active volcano in New Zealand, and has had two very large explosive eruptions in the past 1 ka (Walker et al. 1984; Nairn et al. 2001). Ashfall hazard was chosen because it is one of the most common products of volcanic activity worldwide, and it is a widespread, disruptive hazard that can impact society on many different spatial, temporal, and socio-economic scales (Blong 1984). Ashfall is also a volcanic hazard that is commonly analysed using a probabilistic approach because of the need to consider variable atmospheric conditions (e.g., Scollo et al. 2008; Folch 2012). New Zealand regularly experiences small scale $(\sim 1-2 \mathrm{~mm})$ volcanic ashfalls from its most frequently active volcanoes, with the most recent incidence of minor ashfall occurring in 2012 (Scott and Potter 2014).

\section{Interviews}

A one-on-one semi-structured interview format was used, in which a flexible framework of questions was built around discussion of six maps which were designed to foster discussion of the participants' views on map data classification, colour scheme, content, key expression, and usefulness (Figure 1). Interviews lasted an average duration of 40 minutes. The same probabilistic hazard dataset, showing the probability of accumulating $\geq 10 \mathrm{~mm}$ of ash, was used for all maps (except one), so that only changing map design properties, and not changing data, influenced responses. All maps depicted hazard only for the administrative region in which Tarawera volcano is located, and were viewed at $315 \times 275 \mathrm{~mm}$ size.

Four of the maps showed the hazard data displayed using different data classification styles: gradational shaded (minimum-maximum stretch), isarithmic with solid isopleths (5\% labelled intervals), isarithmic with dashed isopleths (5\% labelled intervals), and binned (10\% intervals). These maps were displayed using a red-yellow multi-hue sequential colour scheme similar to that used commonly in volcanic hazard maps worldwide. The fifth map displayed the data using a blue-yellow-red multi-hue diverging colour scheme similar to that used in other types of hazard maps worldwide (e.g., flooding), and the sixth map showed a deterministic scenario hazard map based on a single pre-determined eruption scenario (i.e., one wind condition and one set of eruptive parameters). A series of cards depicting numerical expressions of percent (10\%), natural frequency (1 in 10), and decimal probability (0.1) and verbal expressions of "probability", "likelihood", and "chance" were also presented for discussion.

Participants were recruited by e-mailing informational flyers to regional and district councils near Tarawera volcano and to the national geological research institute (GNS Science), with encouragement to circulate the information among colleagues, affiliates, and peers who would be interested in participating. Initial contact was made by interested persons contacting the researchers with an expression of interest. A total of 14 people participated in the interviews, including four volcano scientists with specialties in volcano geophysics, monitoring, and hazard analysis, and ten stakeholders with specialties in emergency management, planning, infrastructure and resource management, and public health.

Full transcripts of the semi-structured interviews were analysed using inductive thematic analysis at the semantic level, based on the framework outlined by Braun and Clarke (2006). The transcripts were analysed in order to identify emergent themes regarding how map properties such as data classification, colour scheme, key expression, and content influenced the way the participant thought about or interpreted the map and its usefulness.

\section{Survey}

The online survey comprised 16 pages of 31 questions designed to measure participant views on data classification (Figure 2), map content (Figure 3), key expression, hazard curves (Figure 4), map colour scheme (Figure 5), explanatory text (Figure 6), and map format. These topics were chosen based on their assumed relevance from results of the interviews, literature review, and the prominence of these properties recognised in existing natural hazard maps. The survey is summarised in Table 1 . The survey was based on participants viewing eight different hazard maps styles (Figures 2, 3, 5) and two hazard curve styles (Figure 4), and responding to questions about them. The results of the interviews informed some of the design features used in the survey maps. Seven of the maps showed the exact same probabilistic hazard data, the probability of accumulating $\geq 1 \mathrm{~mm}$ of ash, so that only changing map design properties, and 


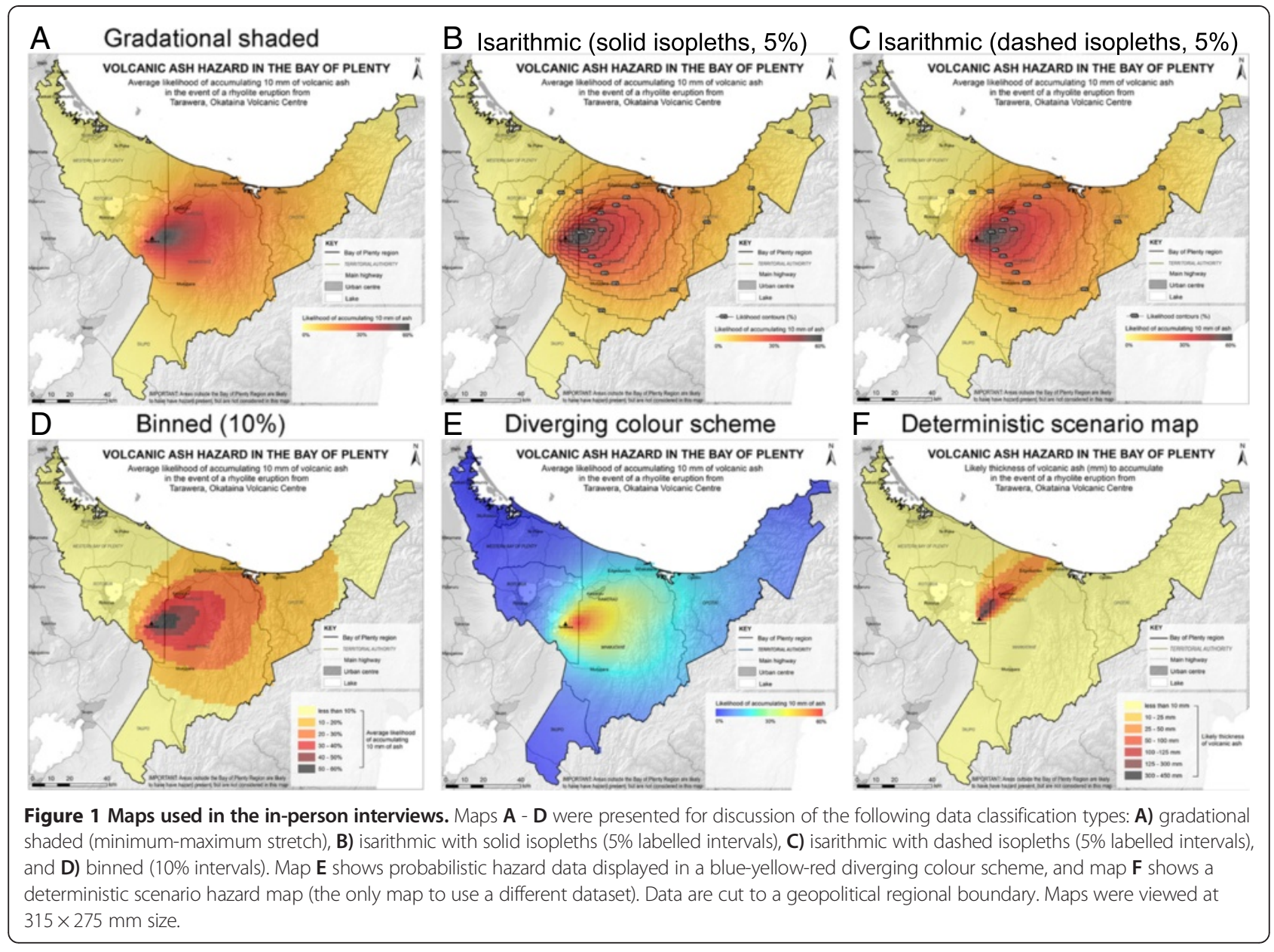

not changing data, influenced responses. The remaining map used the same dataset, but showed a probability threshold (i.e., 25\% probability), instead of an ash threshold (i.e., $\geq 1 \mathrm{~mm}$ ash). All maps were displayed at $150 \mathrm{ppi}$ with a size of $800 \times 710$ pixels (except for colour scheme maps, shown at $584 \times 518$ pixels) and were designed with colour blind-safe 8-bit RGB colour schemes retrieved from the Color Brewer tool (www.colorbrewer2.org, Brewer et al. 2013). Color Brewer is a free, online, researchbacked (Brewer 1996; Harrower and Brewer 2003) tool which provides many colour schemes specifically designed to suit a variety of display environments (e.g., screen or print) and to be colour blind accessible. Participants accessed the free online survey using a custom one-timeuse URL. The survey was open for participation for 41 days. Average time for completion was 25 minutes. A copy of the survey can be found in Additional file 1.

Participants were recruited using a standard snowball sampling methodology. E-mails were sent by the researchers to approximately 50 organisations with a request that the information advertising the survey be circulated to any persons who may use, be interested in, or be involved in the production and editing of, volcanic hazard maps in New Zealand. The e-mail encouraged interested persons to share the survey link with colleagues or associates that they thought may also be interested. All interview participants were also directly invited to participate in the survey. The survey drew 110 participants from a variety of different occupational disciplines, with $29.1 \%$ of respondents in the scientist group, and $70.9 \%$ in the stakeholder group (including 26.4\% in emergency management and planning) (Table 2). The majority of participants (88.1\%) ranged between 25 and 64 years of age, and $88.2 \%$ held an undergraduate or postgraduate/graduate degree (Table 3).

Descriptive and inferential statistical analyses of survey results were performed using IBM SPSS predictive analytics software. Responses to this survey generated primarily non-parametric nominal (i.e., categorical) data, and chi-square tests were used to identify the existence of significant differences within and among samples. Text responses to open-ended survey questions were qualitatively analysed using inductive thematic analysis at the semantic level to identify key patterns and themes. 


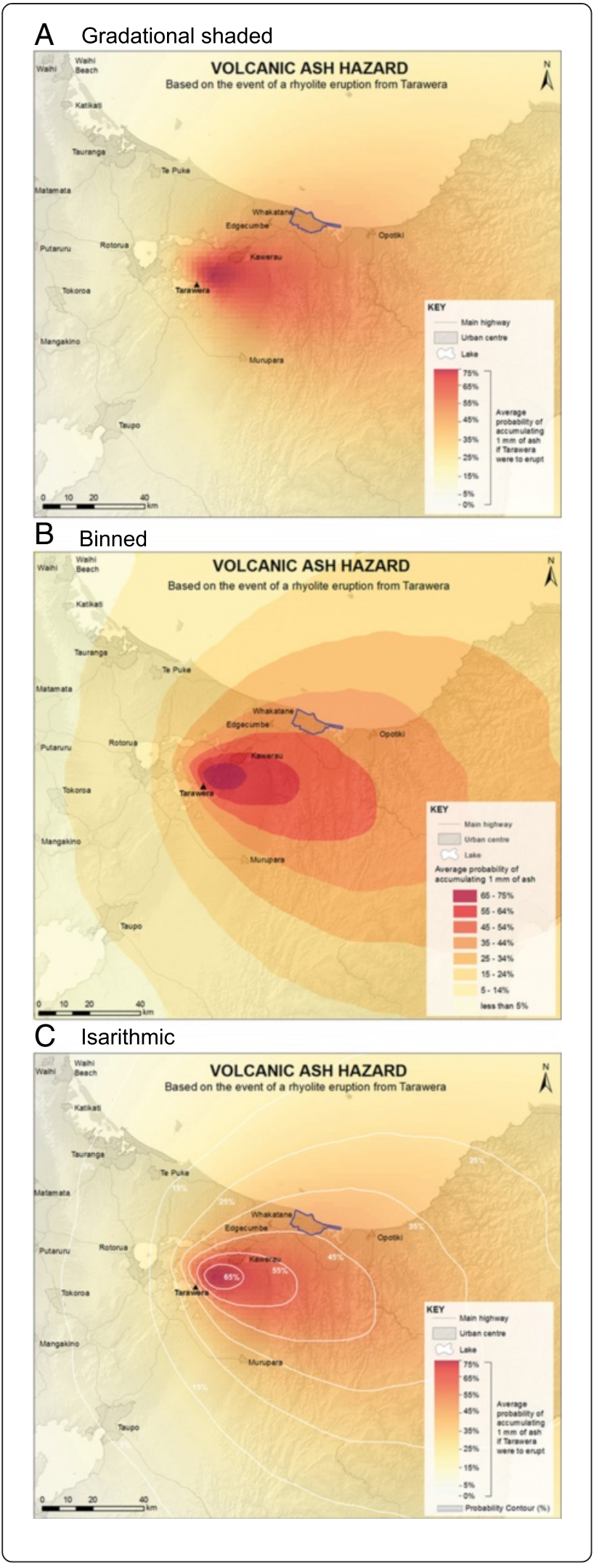

Figure 2 Map images used in the survey (Table 1, Questions 6-13) showing three different probabilistic hazard data classification styles: A) gradational shaded, B) binned, and C) isarithmic. Blue outline shows the urban area of Whakatane for reference purposes here only. In the survey, Whakatane and other areas appeared outlined in grey with grey striped fill underneath the transparent hazard overlay (not clearly visible at reduced size printed here). Seventeen urban areas, main highways, large lakes, and a greyscale digital elevation model underlie the transparent hazard layer as background features. Black triangle represents the location of Tarawera volcano. Maps were viewed at $800 \times 710$ pixels.

\section{Results \\ Interviews \\ Map data classification}

Clarity/ease of reading, precision/uncertainty, and aesthetics emerged as the three primary themes in participants' discussion of map data classification. The ease with which participants were personally able to read data from the map was a motivator for map preference, but participants also expressed consideration of how easy it would be to use the map to communicate with peers and the public:

It's more than just communicating it [the map] to fellow scientists, or fellow emergency managers, or engineers, or whatever. It's also how do you communicate that further down to, to members of the public. - Stakeholder 5

The isarithmic maps (Figure 1B,C) were well-liked and were viewed as accurately portraying the realistic nature of the volcanic ash hazard, while also being easy to read with a high degree of precision:

The advantage is you can still quite easily see the gradational nature of the probability, but at the same time you can read off the actual percentage if you feel you need to read that off. - Scientist 4

No relationship was observed between dashed (Figure 1C) and solid isopleths (Figure 1B) and interpretation of hazard information. However, the black isopleths and labels across the map were viewed as busy and distracting, detracting from the aesthetic appeal of the map. Participants overall recommended smoothing of the isopleths, citing that straight lines and right angles resulting from the square grid used in the model were visually unappealing and could falsely imply certainty. Participants also viewed the $5 \%$ intervals on the isopleths (Figure 1B,C) as misleadingly precise, and instead preferred the $10 \%$ intervals used in the binned map (Figure 1D). 


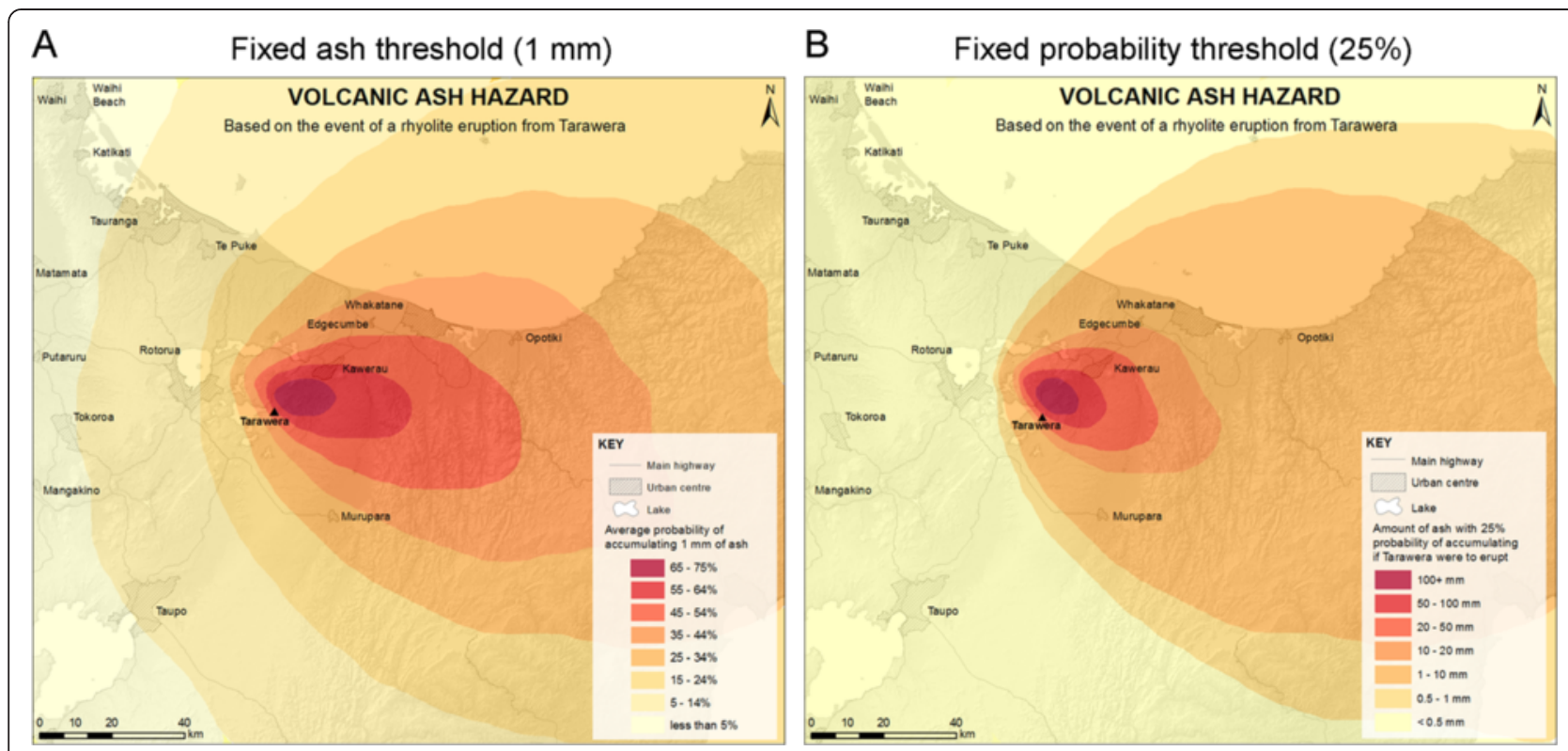

Figure 3 Map images used in the survey (Table 1, Questions 14-15) showing two different types of map content. Map A depicts the hazard using a fixed ash threshold - a distribution of probabilities of reaching and exceeding a fixed ash threshold, here, 1 mm, and map $\mathbf{B}$ depicts the hazard using a fixed probability threshold - a distribution of ash thicknesses expected at a fixed probability threshold, here, 25\%. Key in $\mathbf{A}$ shows binned classes of probability (e.g., 25 - 34\%). Key in B shows binned classes of ash thicknesses (e.g., $1-10$ mm). Maps were viewed at $800 \times 710$ pixels.

The binned map was also well-liked among participants, who viewed it as easy to read and visually appealing. Stakeholder participants also expressed that the binned map allowed for interpreting the map with more certainty, viewing binned zones as "more definitive". Stakeholders also expressed the bins as a useful tool for visualising zones:
Although there's defined areas between them [bins], it's kind of useful in terms of a planning aspect that you've got some boundaries to work on. - Stakeholder 6

However, both scientists and stakeholders expressed that the boundaries between classes on the binned map

\section{A Avg $\mathrm{P}$ with 10th, 90th percentile lines hazard curve}

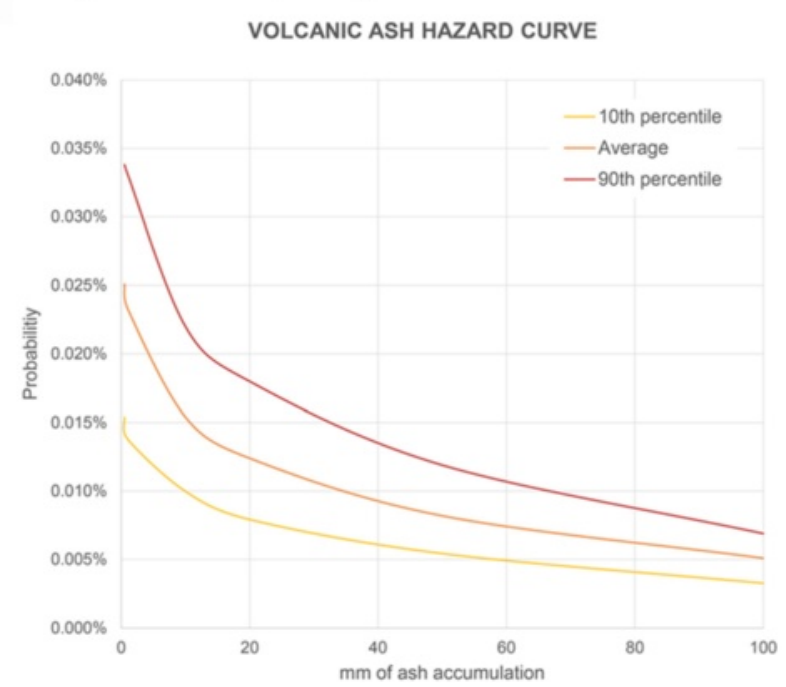

\section{B}
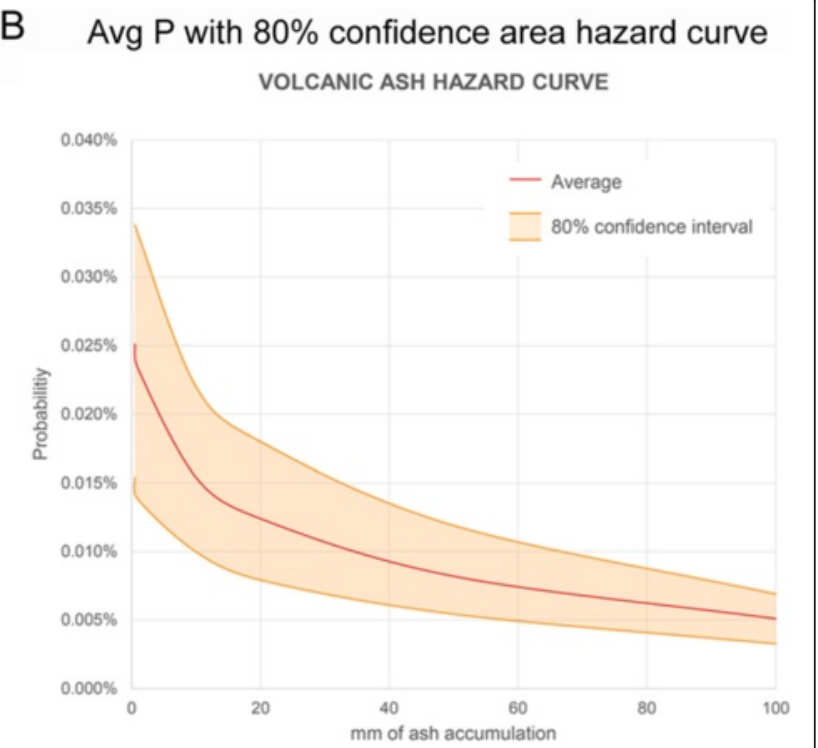

Figure 4 Hazard curves used in the survey (Table 1, Questions 18-22). Both show the same dataset for Whakatane probabilistic ash hazard, but the presentation of the curve in $\mathbf{A}$ shows the average absolute probability, along with the $10^{\text {th }}$ and $90^{\text {th }}$ percentile lines, and in $\mathbf{B}$ shows the average absolute probability, where the area between the $10^{\text {th }}$ and $90^{\text {th }}$ percentile lines is presented as an $80 \%$ confidence interval. Hazard curves were viewed at $800 \times 710$ pixels. 


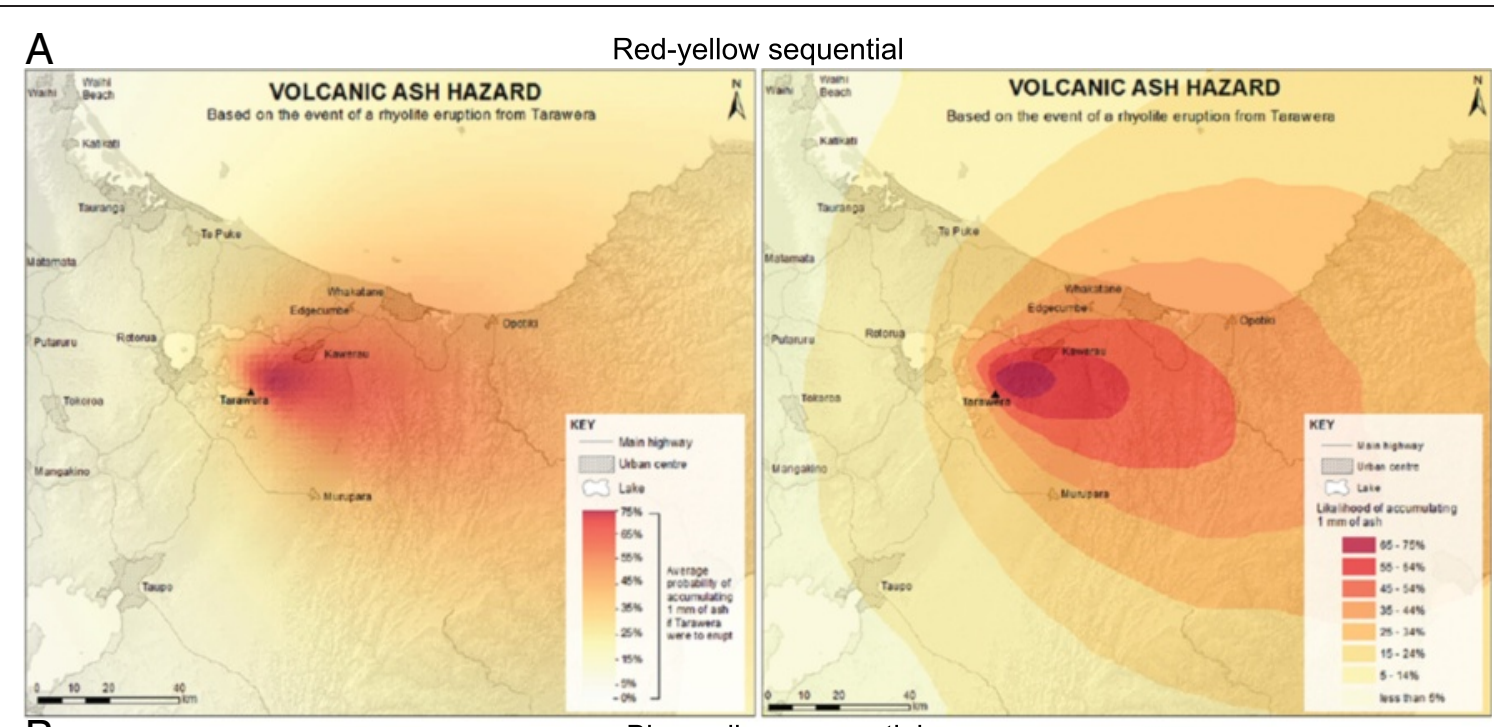

B

Blue-yellow sequential
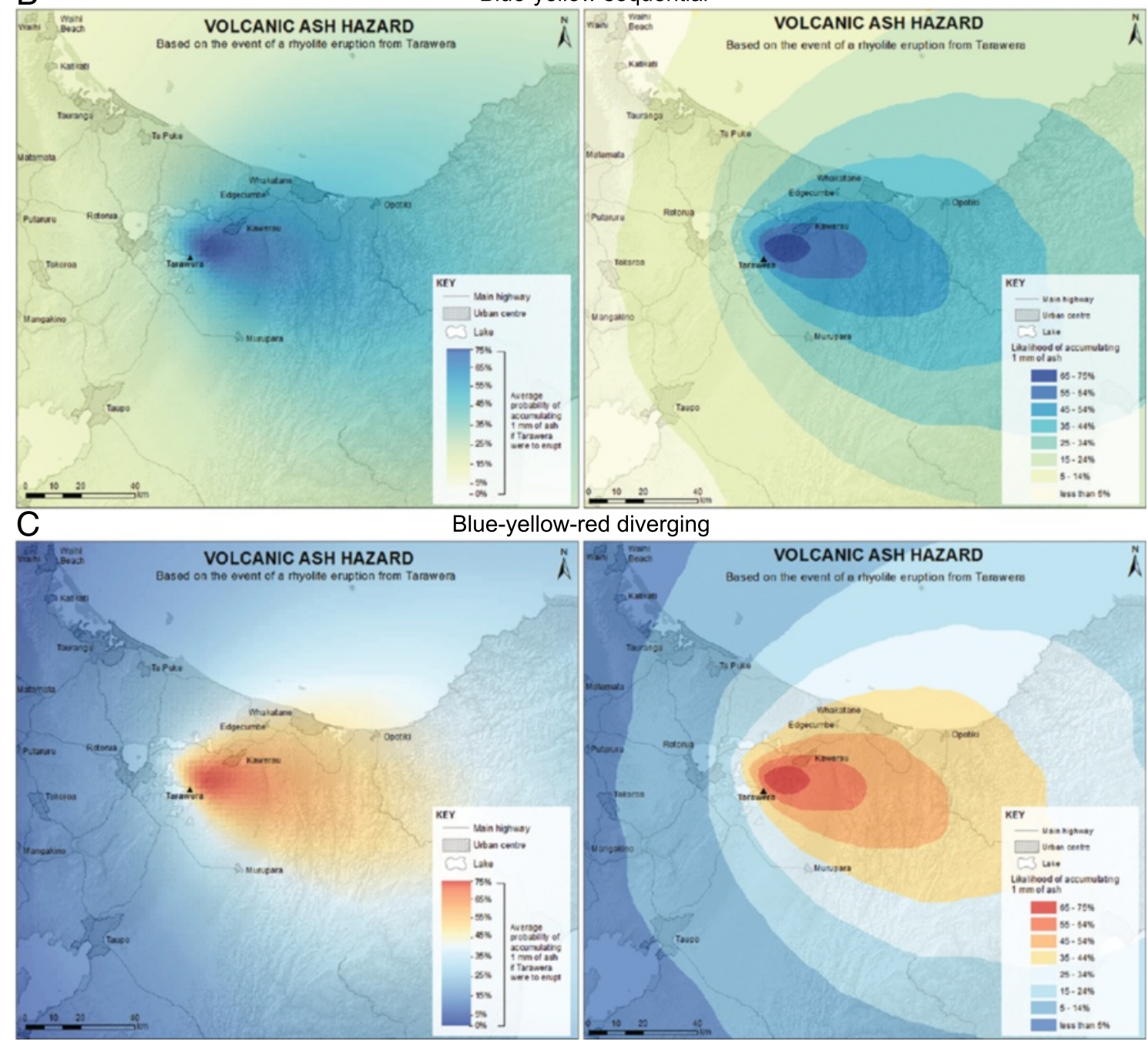

Figure 5 (See legend on next page.) 
(See figure on previous page.)

Figure 5 Maps used in the survey (Table 1, Questions 23-25) showing three different map colour schemes: A) red-yellow sequential, B) blue-yellow sequential, and C) blue-yellow-red diverging. Maps were presented in both gradational shaded (left) and binned (right) data classification format simultaneously so that participants could visualise the colour schemes on different styles of map. Maps were viewed at $584 \times 518$ pixels.

(Figure 1D) could present a disadvantage if they were interpreted as non-gradational or "step-wise":

Except, when you put a boundary on it, then people probably think if they're on one side of the boundary or the other there's a huge difference in probability when there isn't. - Scientist 3

The background content was generally well liked, and viewed as helpful for orientation and location tasks, without cluttering the map. In contrast, geopolitical boundary limits on the data were not liked. Participants suggested that the boundary made the hazard appear to "stop" artificially. Participants also emphasized that managing and responding to hazards is a collaborative process that crosses boundaries, and that uncertainties or unknowns for the hazard in the surrounding regions introduced potential issues for interpretation and application.

\section{Map colour scheme}

Colour associations, zoning, and response emerged as the three primary themes in participants' dialogue concerning map colour scheme. Overall, participants associated red hues with a presence of hazard and blue hues with an absence of hazard. This became particularly important in low probability areas, which would be considered as "safe" if seen in the blue-yellow-red diverging map (Figure 1E), but would still be considered as having a potential to be impacted on the red-yellow sequential map (Figure 1A-D):

My first impression of that [diverging map] is, blue would be safe. Whereas, where this [blue area] is yellow in the other maps, it implies there is some sort of risk that we need to consider. - Stakeholder 2

These associations were described by participants as "subliminal", "genetic", and "psychological". The contrast between hues in the diverging map (Figure 1E) was seen as making the hazard appear smaller, as a localised zone, and was discussed as facilitating distinction between impacted zones in the context of targeting response attention:

It makes it very clear, 'that's the area we're worried about. We're not worried about anything else around the district'. - Stakeholder 7

Stakeholders also observed that the diverging colour scheme appeared very similar to other natural hazard maps that they had experience with:

Automatically [I] relate that to weather maps... and just to complicate matters worse, we're also doing flooding maps, and the models that we use are based very much on the same colour format. So I would look at that straight away and think, 'Oh, it's a flood map.'...because you see the blue. - Stakeholder 8

\section{VOLCANIC ASH HAZARD}

Based on the event of an eruption at Tarawera

Tarawera volcano

Tarawera volcano has experienced at least five large, explosive rhyolite eruptions over its 26,000 year history, with the last one occuring just 700 years ago. A rhyolite eruption could occur at Tarawera again some time in the future. One of the most widespread hazards of rhyolite eruptions is ash fall. Ash fall is considered a very disruptive hazard, but is unlikely to threaten lives.

\section{Probabilistic hazard}

This map shows the average probability of accumulating $1 \mathrm{~mm}$ of ash if a rhyolite eruption were to occur. The values are based on 1,000 computerised simulations of possible eruption scenarios. In the event of an eruption, actual ash fall out would be dependent on wind conditons present at the time of the eruption.
Volcanic ash

Ash particles can be small and very abrasive. Just $1 \mathrm{~mm}$ of ash fall can cause:

- Airport closure

- Irritation to lungs and eyes

- Impaired road visibility and traction

- Possible contamination of water supplies

- Disruption of sewage systems

- Minor damage to vehicles, houses, and equipment

- High water usage from ash clean-up operations

- Damage to electrical equipment and machinery

- Other issues

Figure 6 Explanatory text provided at the top of one of the maps in the survey (Table 1, Questions 26-27). 
Table 1 Summary of questions asked in the online survey Questions in survey

\begin{tabular}{lll}
\hline Question & \multicolumn{1}{c}{ Topic } & Type \\
\hline & Ethics & \\
1 & Understanding of voluntary consent & MC \\
2 & Understanding of access to summary of study findings & MC \\
& Field of work & \\
3 & Primary field of work & MC $^{*}$
\end{tabular}

Personal associations/relevance of volcanic hazard

Experience/memories of volcanoes

$M C^{*}$

Importance of volcanic hazard maps

$\mathrm{MCL}$

\section{Data classification (Figure 2)}

Read probabilistic hazard from gradational shaded map Txt

Read qualitative hazard from gradational shaded map $\mathrm{MCL}$

Read probabilistic hazard from binned map

\section{Txt}

Read qualitative hazard from binned map

$\mathrm{MCL}$

Read probabilistic hazard from isarithmic map

Txt

Read qualitative hazard from isarithmic map

$\mathrm{MCL}$

Order data classification style maps preference

DD

Explain data classification style maps preference

\section{Map content (Figure 3)}

Helpfulness of fixed ash/probability threshold maps

Preferred map to receive of fixed ash/probability threshold maps

\section{Key expression}

Preferred key text

Influence of key text on perceived level of hazard

\section{Hazard curves (Figure 4)}

Read hazard curve with percentile lines Ease/difficulty of reading hazard curve with percentile lines Read hazard curve with confidence interval area Ease/difficulty of reading hazard curve with confidence area Rank helpfulness of hazard curves being available with map

\section{Map colour scheme (Figure 5)}

Preferred colour scheme set of maps

Explain reason for colour scheme preference

Influence of colour scheme on hazard perception

\section{Explanatory text (Figure 6)}

$26 \quad$ Helpfulness of explanatory text to understanding map

Importance of explanatory text on map

\section{Format}

Desired format for receiving volcanic hazard maps

\section{Demographics (Table 2)}

$\mathrm{MCL}$

$\mathrm{MC}$

MC

Txt

$M C L^{*}$
Table 2 Survey participants' occupational discipline

\begin{tabular}{|c|c|c|c|c|}
\hline \multicolumn{5}{|c|}{ Participant occupational discipline } \\
\hline \multicolumn{2}{|l|}{ 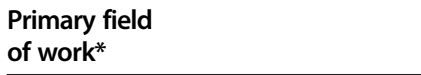 } & \multirow[t]{2}{*}{ Frequency } & \multirow[t]{2}{*}{ Percent } & \multirow[t]{2}{*}{$\begin{array}{l}\text { Cumulative } \\
\text { percent }\end{array}$} \\
\hline Group & Response & & & \\
\hline Scientist ${ }^{* *}$ & $\begin{array}{l}\text { Physical/chemical/earth } \\
\text { science (academic or } \\
\text { scientific organisation) }\end{array}$ & 32 & 29.1 & 29.1 \\
\hline \multirow[t]{9}{*}{ Stakeholder } & Agriculture & 4 & 3.6 & 70.9 \\
\hline & Communication & 3 & 2.7 & \\
\hline & Education & 1 & 0.9 & \\
\hline & $\begin{array}{l}\text { Emergency } \\
\text { management } \\
\text { and planning }\end{array}$ & 29 & 26.4 & \\
\hline & Engineering & 9 & 8.2 & \\
\hline & Government & 17 & 15.5 & \\
\hline & Health & 1 & 0.9 & \\
\hline & $\begin{array}{l}\text { Infrastructure/resource } \\
\text { management }\end{array}$ & 11 & 10.0 & \\
\hline & $\begin{array}{l}\text { Social science } \\
\text { (academic or } \\
\text { scientific organisation) }\end{array}$ & 3 & 2.7 & \\
\hline \multicolumn{2}{|l|}{ Total } & 110 & 100 & 100 \\
\hline
\end{tabular}

*"Response" is taken from participant response to a question about their primary field of work. "Group" is generalised for purposes of comparison in this study, though we acknowledge some participants may identify with both groups. An "other" field was present for those who did not identify with a particular field. However, all responses with an "other" specification also chose a primary field from those provided (e.g., a "statistician" in the physical/chemical/earth sciences).

MC* *For the purposes of this study, a "scientist" is a scientist who specialises in the physical, chemical, or earth sciences.

This was the only significant difference observed between scientists and stakeholders in the interviews. The potential difficulty in reading maps due to colour blindness was raised as an issue by several participants.

\section{Map key expression}

Trust and familiarity emerged as two themes in discussion of key expression. Overall, participants viewed the verbal expressions "probability" and "likelihood" as very similar. However, "probability" was considered by stakeholders to sound more reliable, scientific, and trustworthy, and in that context, it was also interpreted as a more definitive way of expressing the hazard:

Depends on how accurate you want to be. Probability means yes, definitely it is $10 \%$ probable. Whereas $10 \%$ likelihood [means] well it might, it might not.

\section{- Stakeholder 9}

"Chance" was perceived as untrustworthy, and akin to "slang", invoking associations with gambling and horseracing. Percentages (e.g., 10\%) were overall the most preferred numerical expression, with participants explaining 
that they are a commonly used format in many different walks of life. However, some participants noted that natural frequencies (e.g., 1 in 10) were easier for people to get a "feeling" or gist for the value. Decimal values (e.g., 0.1) were universally considered as unfamiliar and too difficult for most people to understand. Many participants also commented that the gradational shaded key symbology was difficult to read with only three percent values marked (min., med., and max.).

\section{Map content}

Participants viewed the probabilistic maps (Figure 1A-E) as long-term planning and reference tools, and as preparedness tools to use in the event of an impending crisis before more detailed deterministic-style maps (e.g., Figure 1F, or an ash advisory bulletin) were available. Participants also expressed that $10 \mathrm{~mm}$ was a high threshold in terms of useful application of the map. Most participants expressed that their primary concern would be the possibility of acquiring any ash at all, explaining that a hazard threshold even as low as 1 to $2 \mathrm{~mm}$ thickness would have very important impacts that they would need to consider:

Any ash to me is the worst case scenario. - Stakeholder 3

Similarly, some participants expressed that probabilistic data for low ash thresholds were helpful supportive content:

I think the probability is more important than the thickness because [of] the way people work. It's, 'Will I get ash?' Not, 'How much will I get?' ... They're not sort of thinking 'We can do this with 10 mill[imetre]s; we can't do this with 100.' It's kind of 'Oh, ok, we have to deal with volcanic ash.' Saying that there's a 30 or 40 percent chance... drives home a pretty strong message that they've got to deal with it. - Scientist 2
Many participants also suggested that addition of text explaining the possible impacts of the ash thickness would make the map more relevant and useful. It was advised that the text be placed directly onto the map face, explaining that it could easily be misplaced, truncated, or disregarded if supplied separately.

\section{Revisions to maps for the survey}

The results of the pilot study interviews which were based on the six maps in Figure 1 informed some revisions to the maps in order to better meet user preferences and needs, resulting in the eight map styles explored in the survey (Figures 2, 3, 5):

- Geopolitical boundary constraint on hazard data removed (Figure 2)

- Colour blind accessible colours were adopted (Figure 3)

- $10 \%$ bins and isopleth intervals were adopted (instead of 5\%)

- More intervals were labelled on the gradational stretch symbology in the key

- White contour lines were used instead of black (to reduce map noise)

- Isopleths were smoothed to remove the jagged artefact of the modelling grid

- $\geq 1 \mathrm{~mm}$ of ash was displayed instead of $\geq 10 \mathrm{~mm}$ of ash.

\section{Survey}

Out of the 110 respondents, seven participants did not fully complete the survey. Results for questions with missing values were measured using only the number of completed responses (min. 103). Results are reported for the 5\% significance level (95\% confidence), where $\chi^{2}$ is the chi-square value for a goodness-of-fit chi-square test (one sample), Pearson $\chi^{2}$ is the chi-square value for a Pearson chi-square test of independence (two or more samples), $\mathrm{df}$ is the degrees of freedom, and $\alpha$ is the level of significance.

Table 3 Participant demographics

\begin{tabular}{|c|c|c|c|c|c|}
\hline \multicolumn{6}{|c|}{ Survey participant demographics } \\
\hline \multicolumn{2}{|l|}{ Age bracket } & \multicolumn{2}{|l|}{ Ethnicity } & \multicolumn{2}{|l|}{ Highest level of education } \\
\hline Group & Percent (\%) & Group & Percent (\%) & Group & Percent (\%) \\
\hline $18-24$ & 4.0 & NZ European & 60.4 & Did not complete high school & 0.0 \\
\hline $25-44$ & 51.5 & NZ Maori & 3.0 & High School/GED & 4.0 \\
\hline $45-64$ & 36.6 & Other European & 27.7 & Vocational/Trade qualification & 6.9 \\
\hline $65+$ & 5.0 & Asian & 0.0 & Tertiary/University degree & 22.8 \\
\hline \multirow[t]{3}{*}{ Prefer not to answer } & 3.0 & Pacific & 0.0 & Postgraduate/Graduate degree & 65.4 \\
\hline & & Other & 6.9 & Prefer not to answer & 1.0 \\
\hline & & Prefer not to answer & 2.0 & & \\
\hline
\end{tabular}


In response to a question about whether they had ever experienced volcanic activity or had any memories associated with volcanic activity (Table 1, Question 4), 68.8\% of participants responded "yes". Of those, $64.0 \%$ described specific volcanic activity in New Zealand. When asked to rank their opinion about how important it is to have a volcanic hazard map for the potentially active volcanoes in New Zealand on a 5-point Likert scale (Table 1, Question 5), 99.1\% of respondents expressed that it was important to some degree, with $73.4 \%$ ranking it "very important".

\section{Map data classification}

Results for questions about data classification (Table 1, Question 6-13; Figure 2) are shown in Figure 7A-D. When reading probabilistic hazard for the $78 \mathrm{~km}^{2}$ urban area of Whakatane, respondents were more likely to give a range of values (e.g., 40 - 45\%) as opposed to a single value (e.g., 40\%) when using the binned data classification map (Figure 2B) $\left(\chi^{2}=114.919, \mathrm{df}=1, \alpha<0.001\right)$ or the isarithmic map (Figure $2 \mathrm{C})\left(\chi^{2}=117.237, \mathrm{df}=1\right.$, $\alpha<0.001$ ) (Figure 7A). In contrast, respondents were

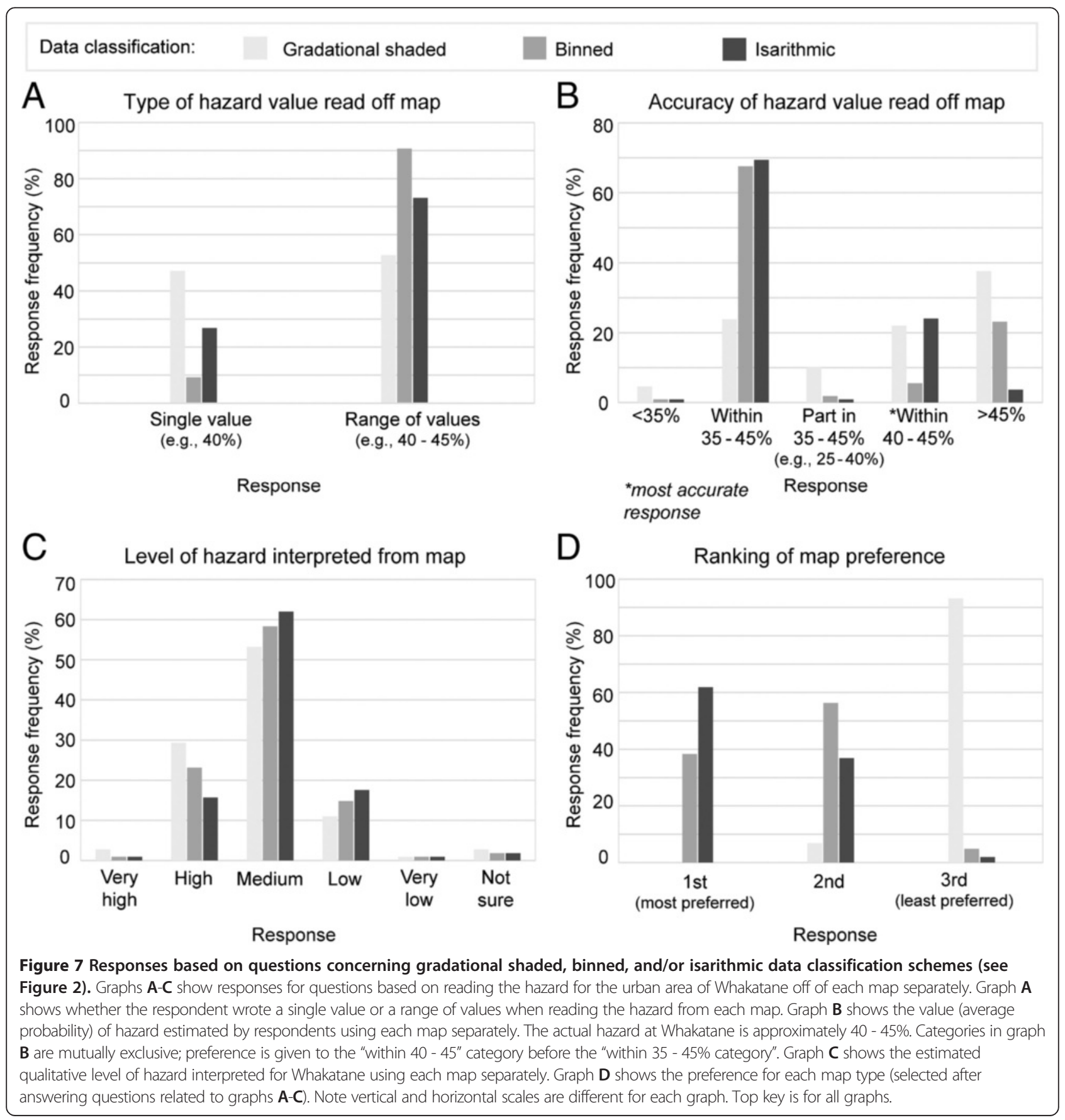


equally likely to give either a range of values or a single value when using the gradational shaded map (Figure 2A) $\left(x^{2}=0.092, \mathrm{df}=1, \alpha=0.762\right)$ (Figure 7A). Of those who responded with a range, more participants (17.9\%) reported a $5 \%$ interval range when using the isarithmic map (Figure 2C) than for any other data classification map style. Ten percent ranges were the most commonly estimated range interval for all data classification types. The actual hazard values for Whakatane ranged between approximately $40-45 \%$. When reading hazard from the isarithmic map (Figure 2C), respondents were more likely to estimate a single or range of values within $40-45 \%$ (very accurate) or $35-45 \%$ (generally accurate) than when using the other two maps (Figure 7B). When using the gradational shaded map (Figure $2 \mathrm{~A}$ ), respondents were more likely to under- or over-estimate the hazard value (Figure 7B).

More than half of respondents interpreted the qualitative level of hazard as "medium" regardless of map data classification style used (Figure 7C). The level of qualitative hazard interpreted from each map did not change for $71.8 \%$ of respondents who chose only one hazard level for all three maps. Scientists were more likely to show a change in the level of qualitative hazard interpreted from the different maps than stakeholders (Pearson $\chi^{2}=7.987$, $\mathrm{df}=2, \alpha=0.018$ ), with $40.0 \%$ of scientists choosing two hazard levels among the three maps, and 3.3\% choosing three, and $25.0 \%$, and $0.0 \%$ of stakeholders choosing two and three levels of hazard, respectively.

The isarithmic data classification map (Figure 2C) was ranked as the most preferred map choice, and the gradational shaded map (Figure 2A) was ranked the least preferred (Figure 7D). There was no difference in the preferences of scientists and stakeholders, with $37.5 \%$ of both scientists and stakeholders preferring the binned data classification map (Figure $2 \mathrm{~B}$ ), and $62.5 \%$ preferring the isarithmic (Figure 2C) (Pearson $X^{2}=0.000, \mathrm{df}=1, \alpha=$ 1.000). Respondents wrote an average of 30 words in response to an open-ended text question about map data classification style preference. Three main themes emerged concerning the influence of map data classification style on respondent's interpretation of the hazard map: clarity/ease of reading, precision/uncertainty, and realistic hazard representation. Many respondents stated that the presence of gradational shading (Figure 2A,C) was favourable because it represented the gradational nature of ashfall hazard more realistically:

Clearest because it shows that the hazard is gradational, steadily decreasing away from the source. - Scientist 30

Similarly, the binned map (Figure 2B) was seen by many users to be an unrealistic portrayal of ash hazard:
The [actual] change is gradational, so [the binned map] is too stepwise. Gives the wrong impression. - Stakeholder 54

However, using gradational shading only (i.e., without isopleths) (Figure 2A) was overall seen as requiring too much effort to read with any degree of precision. When labelled probability isopleths were included on the gradational shaded map, many participants found the resulting isarithmic map (Figure 2C) much easier to read with a higher degree of precision:

[It is] instantly obvious which range of values an area falls within, plus you can see where in the range it falls, so you can get quite a precise value just by quickly looking at the [isarithmic] map. - Stakeholder 87

Less reliance on the key symbology was also seen as increasing precision:

The labels indicating the probability band removes any confusion associated with the colour symbology. - Scientist 104

\section{Map content}

Results for questions about map content (Table 1, Question 14-15; Figure 3) are shown in Figure 8A-B. Both types of map content investigated (Figure 3 ) were viewed as helpful to some degree by the majority of respondents, with $95.2 \%$ of respondents ranking the fixed ash threshold map (Figure 3A), and 89.4\% ranking the fixed probability threshold map (Figure 3B), as very helpful, helpful, or somewhat helpful (Figure 8). Among the $97.2 \%$ of respondents who chose a preference, no statistically significant difference exists between preference for receiving a map with content describing a fixed ash threshold, a fixed probability threshold, or one of each $\left(\chi^{2}=1.529, \mathrm{df}=2, \alpha=0.465\right)$. There was no statistically significant difference in the preferences of scientists and stakeholders (Pearson $\chi^{2}=2.111, \mathrm{df}=2, \alpha=0.348$ ).

\section{Map key expression}

Results for questions about key expression (Table 1, Question 16-17) are shown in Figure 9. When presented with three different combinations of verbal and numerical phrases of probabilistic hazard in the map key, $73.4 \%$ of respondents said the phrases used did not change the level of hazard they interpreted from the map. However $14.6 \%$ of respondents thought that the natural frequency expression ( 1 in 4 ) made the hazard seem greater than the percentage (25\%). Despite the majority of respondents saying that the key had no influence on hazard perception, $93.2 \%$ of respondents chose a preferred key expression (Figure 9). More than half of 


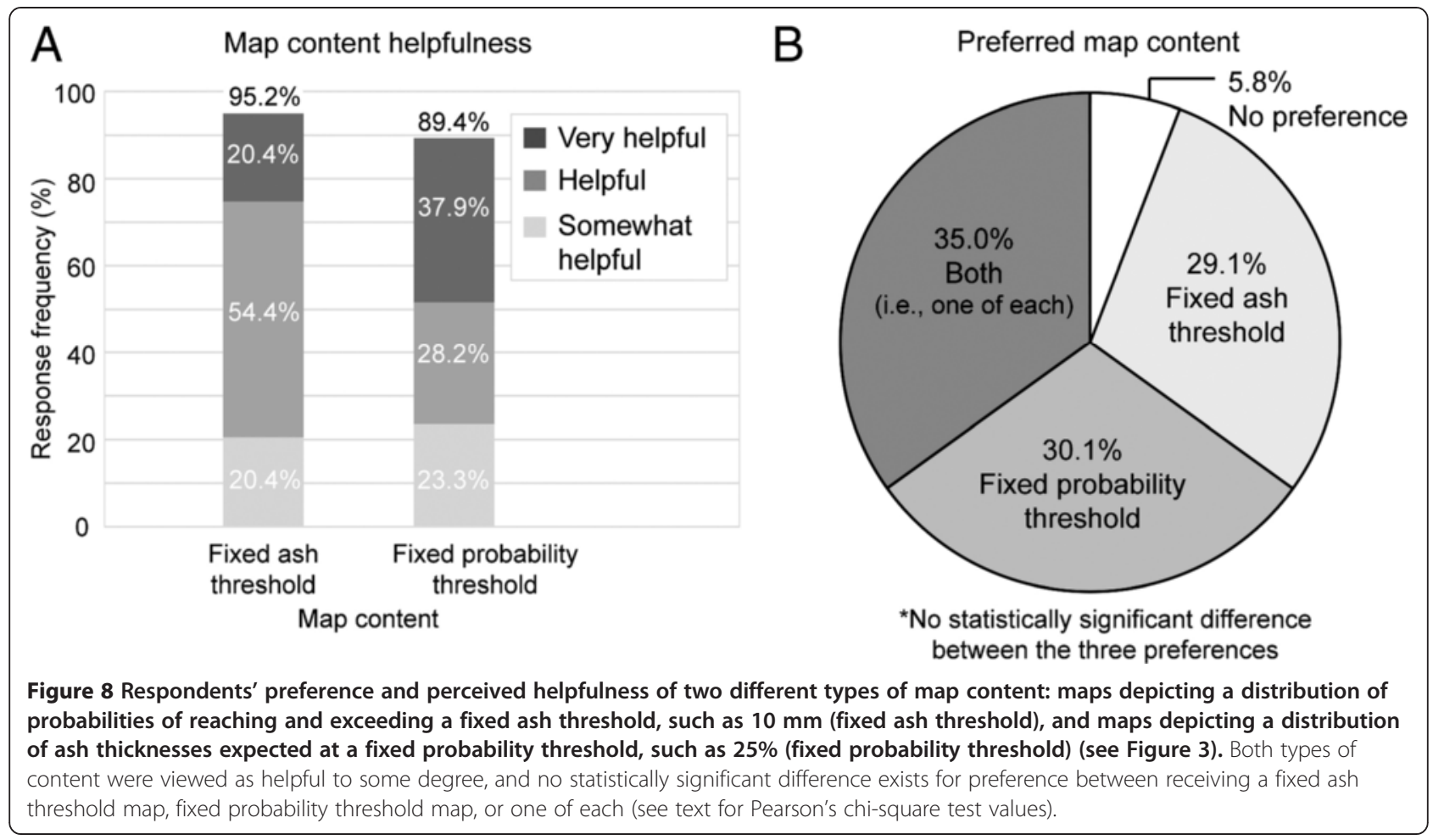

respondents preferred having both a percent "probability" and natural frequency "likelihood" expressed in the key. The second most preferred key expression was a percent probability. Of the $22.3 \%$ of respondents who entered text as optional commentary, many described

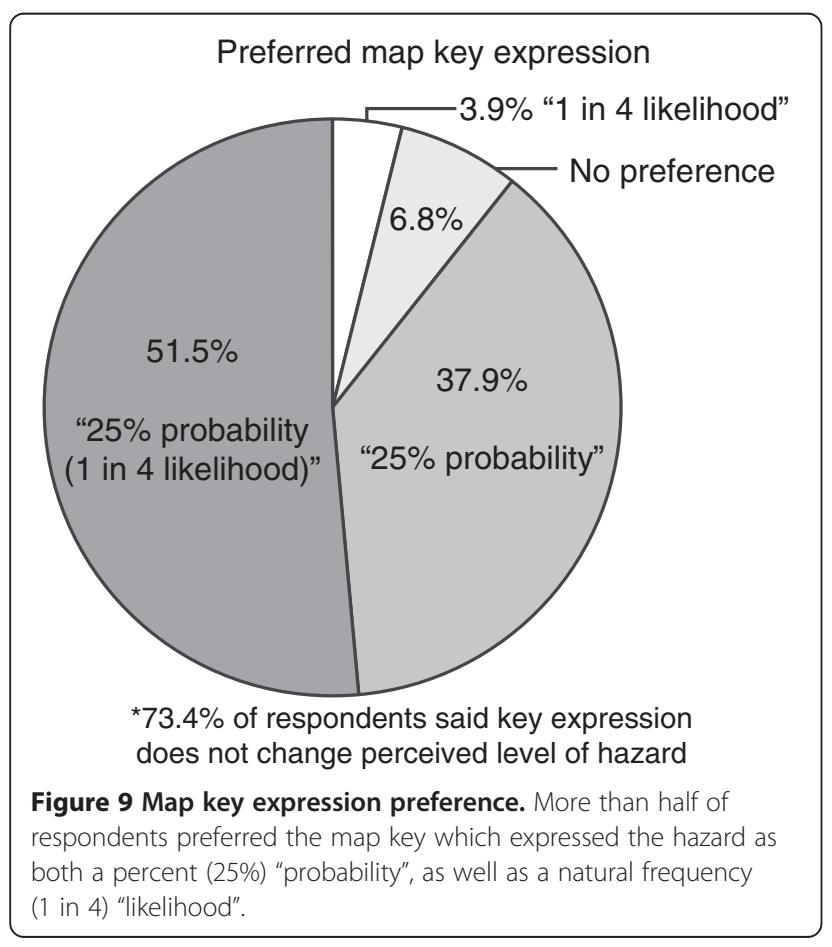

the key with a natural frequency "likelihood" expression only as "amateurish", "subjective", and "awkward", with one respondent citing that "likelihood" has a different and specific meaning in their field of work. Percent probability was generally described as a common, familiar expression that was readily understood by both professionals and the public. Some respondents suggested that providing the natural frequency likelihood alongside a percent probability may help the message be received by a larger audience. No significant difference existed in the key expression preference of scientists and stakeholders (Pearson $X^{2}=0.892, \mathrm{df}=3, \alpha=0.892$ ).

\section{Hazard curves}

Results for questions about hazard curves (Table 1, Question 18-22; Figure 4) are shown in Figure 10A-B. When ranking how helpful it would be to be provided with hazard curves for chosen locations on the map, $55.4 \%$ of respondents said the curves were very helpful, helpful, or somewhat helpful. However, scientists found the hazard curves significantly more helpful than stakeholders, with $73.3 \%$ of scientists ranking the curves as helpful to some degree, while only $48.1 \%$ of stakeholders did (Pearson $\chi^{2}=6.324, \mathrm{df}=2, \alpha=0.042$ ). Nine percent of stakeholders were not sure about the helpfulness. Performance in reading a hazard curve for Whakatane improved significantly when respondents used the hazard curve with the $80 \%$ confidence area (Figure 4B), with $70.3 \%$ of respondents choosing the most correct answer, 
Avg $P$ with 10th, 90th percentile lines hazard curve

\section{A Response variation in reading hazard curves}

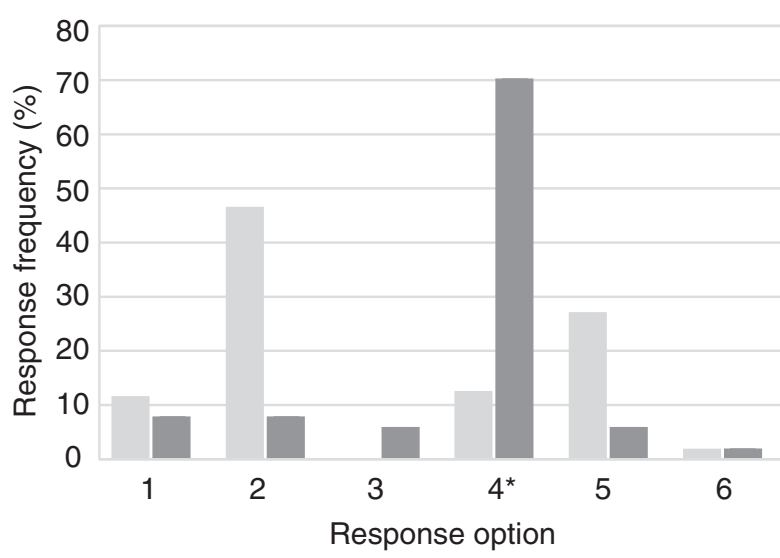

${ }^{*}$ correct response
Avg $\mathrm{P}$ with $80 \%$ confidence area hazard curve
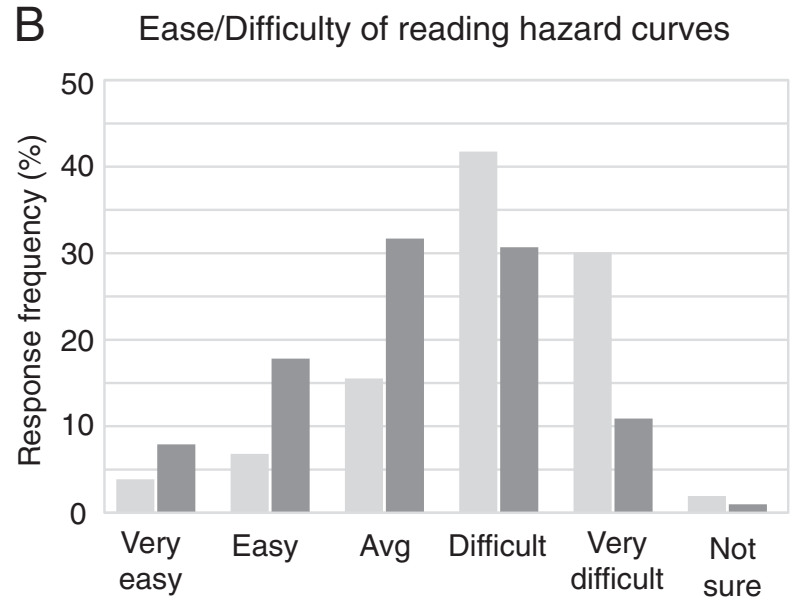

Response

Figure 10 Responses based on separate questions in which respondents used a hazard curve for a point in the urban area of Whakatane drawn with average probability, $10^{\text {th }}$, and $90^{\text {th }}$ percentile lines, and then with average probability and an $80 \%$ confidence area (see Figure 4). Graph $\mathbf{A}$ shows the frequency at which six possible responses were chosen using each hazard curve for a question which required the respondent to read information from the curve and choose which statement was the most true. Response option four is the most correct answer. Graph B shows the level of ease/difficulty respondents reported for reading information from each hazard curve.

compared to $12.6 \%$ when using the hazard curve with $10^{\text {th }}$ and $90^{\text {th }}$ percentile lines (Figures $4 \mathrm{~A}, 10 \mathrm{~A}$ ). More than $46 \%$ of respondents chose a response option in which the $10^{\text {th }}$ percentile was incorrectly described as $10 \%$ confidence when using the hazard curve with $10^{\text {th }}$ and $90^{\text {th }}$ percentile lines (Figure $4 \mathrm{~A}$ ), compared to just
$7.9 \%$ when using the hazard curve with $80 \%$ confidence area (Figure 4B) (response option 2, Figure 10A). In describing the ease/difficulty of reading the two hazard curves, $71.9 \%$ of respondents found the curve with $10^{\text {th }}$ and $90^{\text {th }}$ percentiles difficult or very difficult to read, and $26.2 \%$ found it average, easy, or very easy, compared

\section{A Colour scheme influence on hazard perception}
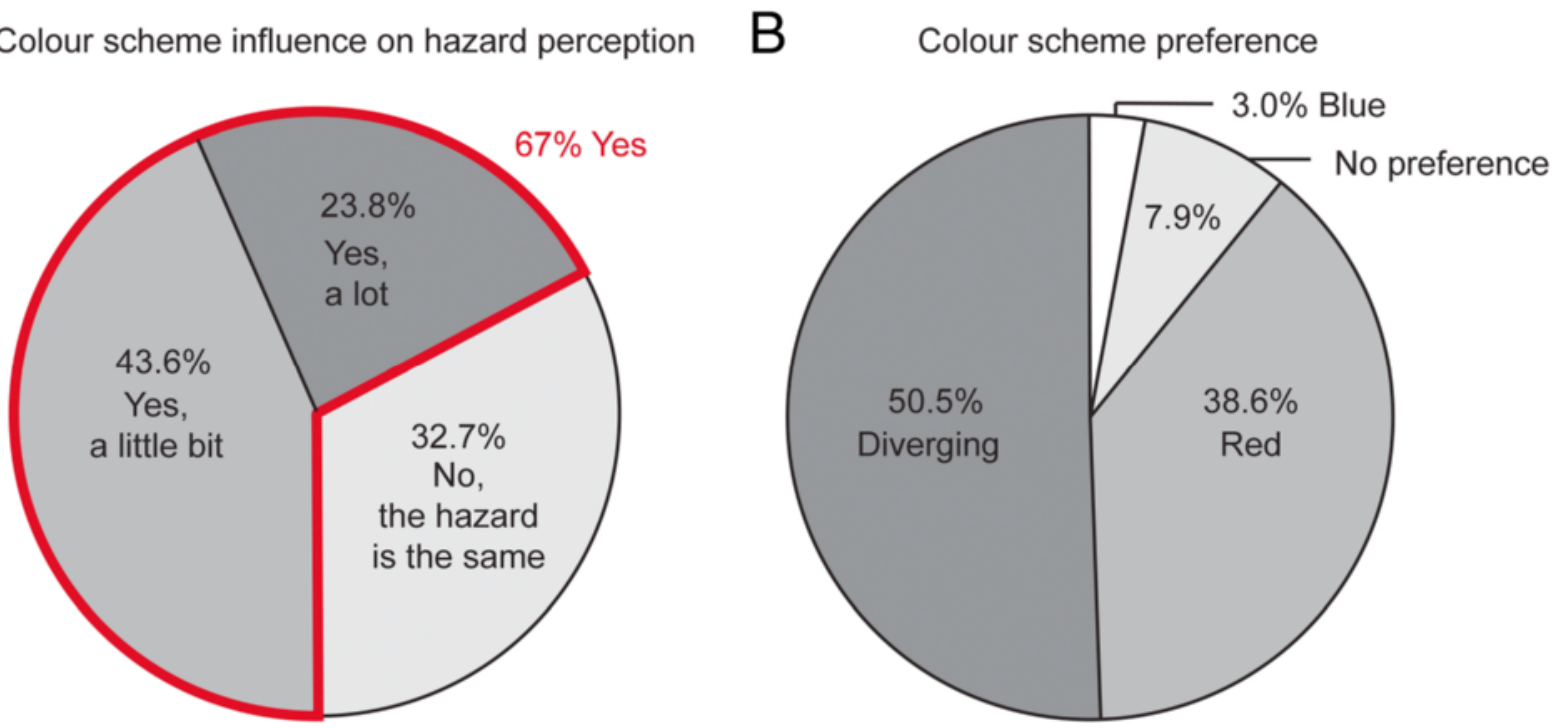

Figure 11 Responses pertaining to A) the degree to which map colour scheme influences hazard perception, and B) preference between blue-yellow sequential (blue), red-yellow sequential (red) and, blue-yellow-red diverging (diverging) colour schemes on probabilistic volcanic hazard maps (see Figure 5). The majority of respondents (67.3\%) agreed that colour scheme influenced their perception of hazard, with diverging and red being the two most preferred colour schemes. 


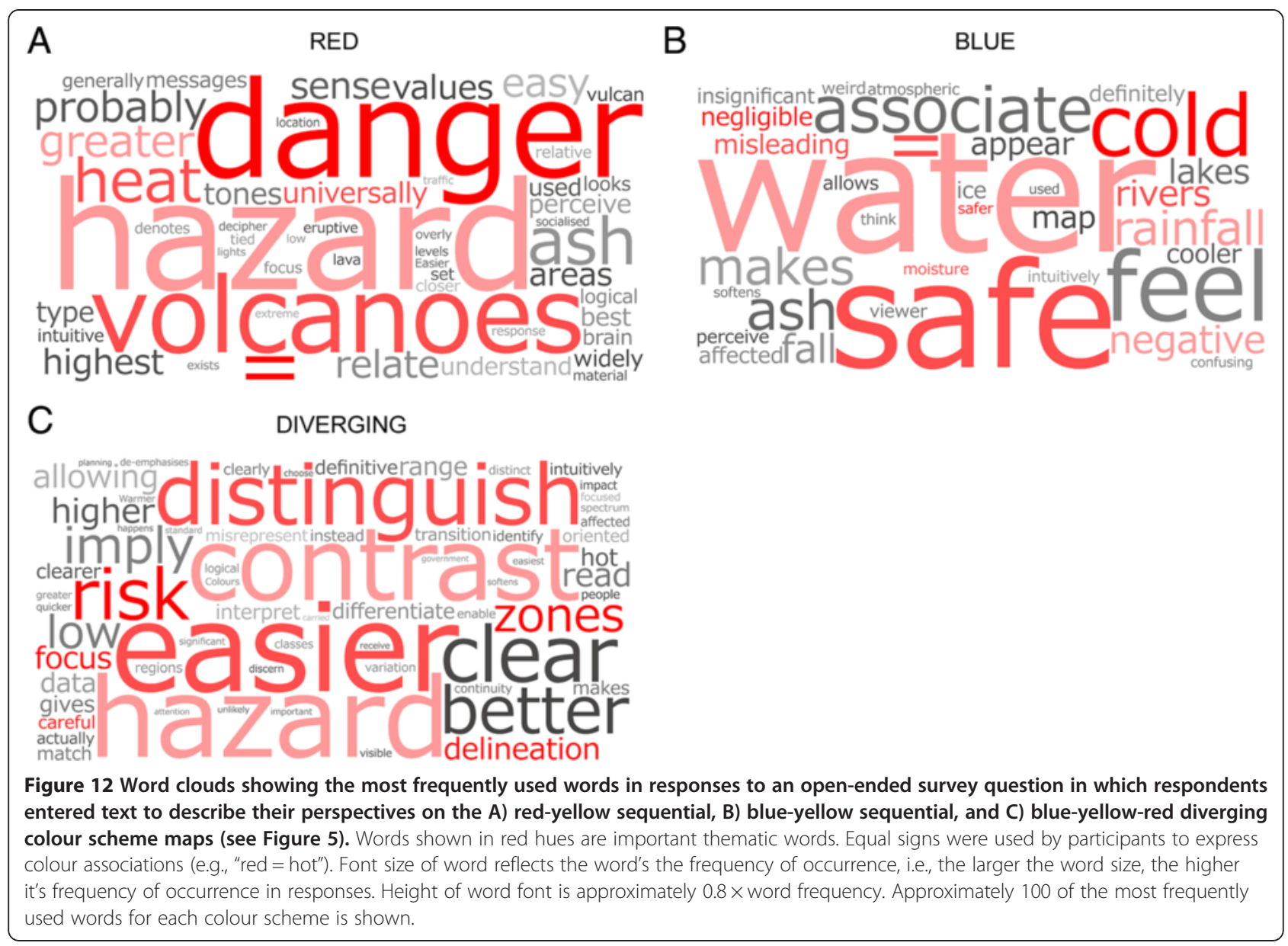

to $41.6 \%$ and $57.4 \%$ of respondents for the $80 \%$ confidence area curve, respectively (Figure 10B).

\section{Map colour scheme}

Results for questions about colour scheme (Table 1, Question 23-25; Figure 5) are shown in Figure 11A-B and Figure $12 \mathrm{~A}-\mathrm{C}$. For more than $67 \%$ of respondents, colour scheme had an effect on how they perceived the level of hazard $\left(\chi^{2}=14.957, \mathrm{df}=2, \alpha=0.001\right)$ (Figure 11A). The blue-yellow-red diverging colour scheme ("diverging") (Figure 5C) and red-yellow sequential colour scheme ("red") (Figure 5A) were the most preferred colour schemes (Figure 11B). Among the top two preferred colour schemes, chosen by $89.1 \%$ of respondents, the red map (Figure $5 \mathrm{~A}$ ) was preferred by a majority $59.3 \%$ of scientists, and the diverging map (Figure $5 \mathrm{C}$ ) was preferred by a majority $64.3 \%$ of stakeholders (Pearson $\chi^{2}=$ 5.072, df =1, $\alpha=0.024)$.

Respondents wrote an average of 16 words when explaining their map colour scheme preference. Four main themes emerged concerning the influence of colour scheme: colour associations, cultural/social/mental connotations, zoning, and risk and response. Figure 12 highlights the words most frequently used by respondents in discussion of each colour scheme. Red hues were associated with concepts of danger, the presence of hazard, and volcanoes (Figure 12A). In contrast, blue hues were associated with concepts of safety, the absence of hazard, and water (Figure 12B):

\section{Red always denotes hazard to me. - Stakeholder 89}

The blue looks negative rather than low. The colour blue is usually associated with water. - Stakeholder 57

Many respondents remarked that the colour associations were evoked by cultural, social, or psychological connotations. Respondents used words such as "intuitively", "universally", "subliminal”, "socialised", "logical”, and "used worldwide", to describe the reasons for their strong associations with the colours red and blue. The associations with red and blue colours were consistent for both diverging and sequential colour schemes:

[The diverging map] give the impression of safety [in the blue areas] and emphasizes danger in the red areas... 


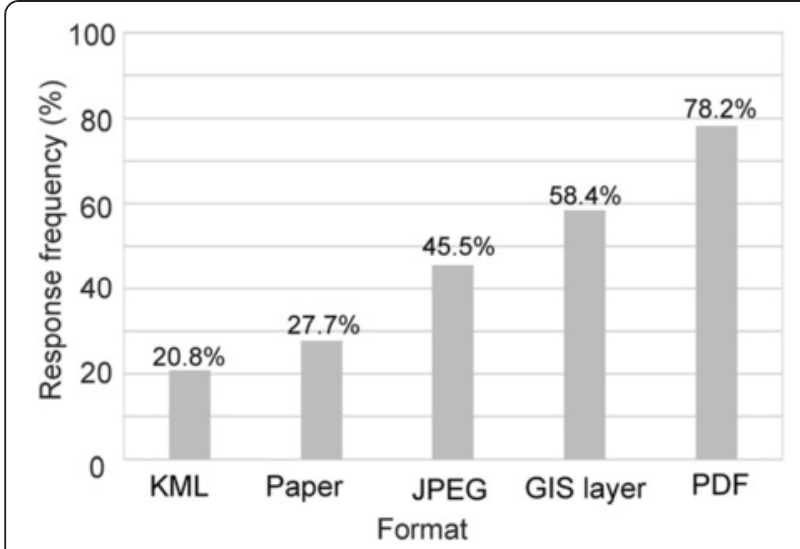

Figure 13 Desired formats for receiving volcanic hazard maps. Participants could choose one or more of the five formats, GIS layer, JPEG, KML, paper, or PDF, or write in an alternative one. More than one option was chosen by $75.3 \%$ of respondents. The format preferred most by respondents was PDF (78.2\%).

[The red map] gives the impression of increasing danger closer to the volcano. - Scientist 99

Red-blue seems to imply hazard and non-hazard, instead of hazard and less hazard. - Stakeholder 58

When describing the diverging colour scheme map, many respondents explained that they liked that the contrast made it much easier to "distinguish" and "delineate" the map into discrete "zones" (Figure 12C). However, the zones of colour had different context for different users. While responses describing the red map primarily focused on describing the map in the context of hazard, there was a marked increase in discussion of "risk" with the diverging colour scheme map among stakeholders (Figure 12B,C):

The blue de-emphasises lower likelihood areas allowing for a more risk-based focus. - Stakeholder 46

In some cases, the area of transition for the divergent colours was explicitly linked to response action:

The transition between hot and cold colours should be carefully set at a standard point, as anywhere in cold colours is unlikely to receive attention when planning in government departments is carried out. - Stakeholder 91

\section{Map explanatory text and map format}

In responding to questions about explanatory text (Table 1, Question 26-27; Figure 6), 94.1\% of respondents said that providing informative text about the volcano, probabilistic hazard, and possible volcanic ash impacts on the map was helpful to some degree. The same proportion of respondents also viewed explanatory text on the map as important to some degree, with $50.5 \%$ ranking it "very important". Results for questions about map format (Table 1, Question 28) are shown in Figure 13. The most popular format for receiving volcanic hazard maps was PDF, followed by GIS layer and JPEG (Figure 13). More than three-quarters of respondents $(75.3 \%)$ chose more than one of the five format options provided.

\section{Discussion}

\section{Data classification and uncertainty}

Regardless of map data classification style viewed (Figure 2), more than half of survey participants considered the probability of accumulating $\geq 1 \mathrm{~mm}$ of ash in Whakatane as a "medium" level of hazard (Figure 7C). Few participants, and particularly few stakeholders, changed the qualitative descriptor used, even when their estimates of numerical value varied between maps, highlighting that qualitative descriptors of hazard may have less sensitivity for reflecting subtle perceived changes in hazard data. This demonstrates possible issues with relying on a broad verbal probability translation table for volcanic uncertainty, and emphasises the importance of including numerical values along with qualitative descriptors of probability as suggested by Doyle et al. (2011) and Budescu et al. (2009).

Estimates of hazard read from a probabilistic hazard map displaying only a gradational shaded stretch of values (Figure 2A) were less consistent than for other data classification types (Figure 7A,B), which suggests that there is low reliability in the way users may read and interpret information from this style of map. The vast majority of participants also ranked the map as least preferred (Figure 7D) or expressed dislike, which could manifest in practice as an aversion to using and applying maps with data presented in this style. However, the addition of probability isopleths dramatically improved the favourableness and readability of gradational shaded data classification. The isarithmic map (Figure 2C) was the most preferred (Figure 7D) and most accurately-read data classification style (Figure 7B). Presence of isopleths also increased the frequency of reading hazard as a range of values instead of a single value (Figure 7A), which is a more accurate estimation of hazard for the $78 \mathrm{~km}^{2}$ area of Whakatane (actual hazard $40-45 \%$, Figure 2). Expressing a range of values may have positive implications for practice, as Dieckmann et al. (2010) found that using a range of probabilities to express uncertain information is likely to be considered more credible and responsible in a decision-making context than use of a single value probability. 
The isarithmic data classification (Figure 2C) also appeared to enhance the level of map engagement, by encouraging participants to critically assess the map and estimate a more precise range of probabilities. Reading the gradational shaded map (Figure 2A) required participants to spend increased effort, only to achieve a broad variation in accuracy and a low level of consistency in responses. Reading the binned map (Figure 2B) facilitated quick perception of a range of hazard with little effort, but the majority of respondents read this as "definitive" and did not elaborate beyond the $10 \%$ accuracy conveyed in the map key. When reading the isarithmic map (Figure 2C), participants were able to quickly and easily estimate a $10 \%$ range of hazard, and more participants opted to critically assess the shading within the $10 \%$ interval to increase the precision of their estimate to within $5 \%$ accuracy (Figure 7B). The non-discrete "fuzzy" appearance of gradational shading is considered an appropriate strategy to depict uncertain hazard and risk information (MacEachren 1992; Slocum 1999), and our results suggest that adding isopleths to this style effectively improves reader ability to interpolate shading for those who seek to reduce uncertainty.

Concern about precision and uncertainty in the modelled data was a primary theme regarding data classification in both the interviews and the surveys. For example, most participants found $5 \%$ interval isopleths (Figure 1B,C) unfavourable because they appeared to depict "unwarranted" precision or certainty. The prominence of uncertainty and precision in discussion of the maps suggests that it is recognised as an important component of probabilistic volcanic hazard data by both scientists and stakeholders. Donovan et al. (2012) found that effective communication and acknowledgement of uncertainty among both groups was critical for achieving useful application of probabilistic volcanic hazard and risk data in decision-making during volcanic crises at Montserrat. However, uncertainty in volcanic hazard maps is not always recognised or accepted, and it is important to explore how users perceive and approach uncertainty in maps. In the context of map properties, our results indicate that depicting $10 \%$ intervals in probability may be perceived as appropriate, adequate, and accessible for visualising and processing hazard information among a diverse group of users.

As a whole, participants expressed a general understanding that there are uncertainties associated with modelled probabilistic volcanic hazard data. However, more specific concepts of uncertainty related to the nature of the probabilistic data were less clear. The concept and meanings of lower and upper percentile values were not consistently or easily understood by the majority of participants when reading from a hazard curve (Figure 10). A hazard curve displaying the concept of confidence (Figure 4B) was better understood, with more participants also finding it easier to read than the curve with percentiles (Figure 4A). These differences have important implications for the language and graphics we use to communicate probabilistic hazard. As probabilistic tools such as volcanic hazard curves become more integrated in volcanic hazard and risk management (e.g., Tonini et al. in press), it is important to understand the contextual measures which can be implemented to improve the presentation of results and achieve clearer communication, particularly because statistical interpretation is a common challenge for many people (Reyna and Brainerd 2008).

\section{Colour scheme and messages of hazard}

The emergence of "risk and response" as a theme associated with the diverging colour scheme showed that the concept of hazard was also ambiguous in some cases. Volcanic hazard refers to the possible occurrence of a dangerous or destructive volcanic phenomenon, and can vary in frequency, magnitude, and spatial extent. In contrast, volcanic risk implies consideration of both the hazard and the vulnerabilities and capacities of people and communities in the areas exposed to the hazard (Fournier d'Albe 1979; UNISDR 2009). While the volcanology community agrees that scientists are responsible for analysing and communicating hazard, the role of scientists regarding volcanic risk and response advice is more controversial, as risk-based decision-making must take into account many social, political, and economic factors (Marzocchi et al. 2012). The diverging colour scheme (Figure 5C) was preferred by a significantly greater proportion of stakeholders than scientists, as this group may have a greater propensity for seeking risk-related information. Our results suggest that unintended messages or connotations of risk and risk-based response may be avoided by using sequential, rather than diverging, colour schemes to illustrate hazard. Diverging hues convey messages of a changing state or phenomena (Slocum 1999), such as a safe state and a dangerous state. In contrast, adjusting lightness and saturation of incremental hues on a sequential scale conveys a message of changing intensity or degree (Slocum 1999), recognised in the participants' perception of low, but not absent, hazard in light yellow-coloured areas on the red colour scheme map (Figure 5A). Sequential hue colour schemes have also been found to convey changing intensity in health risk maps (Severtson and Vatovec 2012; Severtson and Myers 2013).

The stakeholder participants' tendency to observe "confusing" similarities between the diverging colour scheme volcanic hazard map (Figure 5C) and hydrological-type hazard maps highlights the fact that many stakeholders are often responsible for dealing with many different types of hazard and risk. Despite volcanic ash not being a high- 


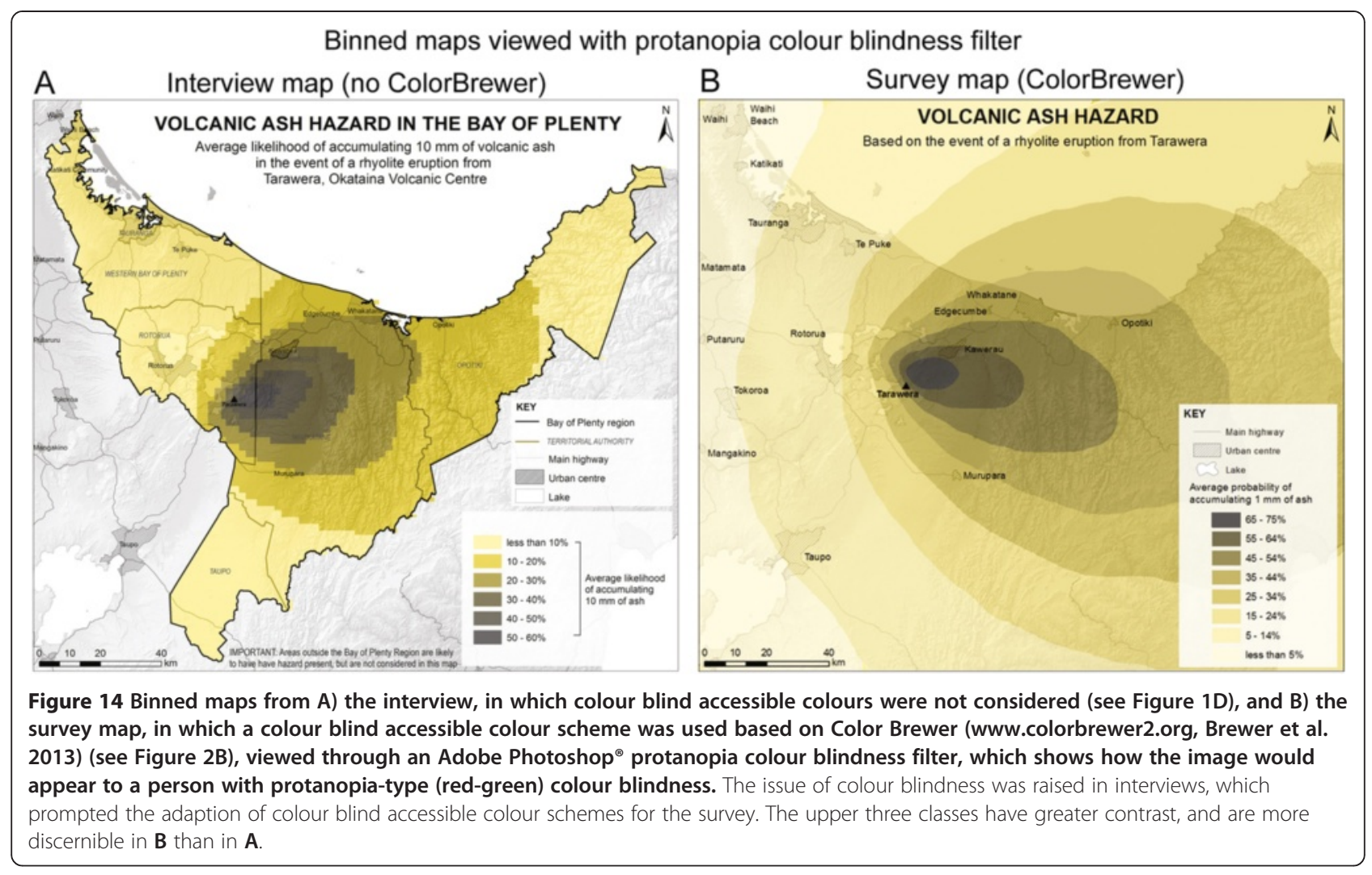

temperature phenomenon, the associations of "hot" volcanoes with the red map (Figure 12A) suggests that using warm colour schemes may make volcanic hazard maps distinguishable for users who frequently encounter hazard and risk maps for other phenomena. Improvement in the colour contrast of the maps from the interviews to the surveys emphasizes the importance of selecting colour blind accessible colour schemes. Color Brewer (Brewer et al. 2013) was an effective and simple tool for choosing colour blind accessible map colour schemes, and filters which show how the map is likely to appear to a colour blind reader, such as those offered in Adobe Photoshop', or in the free online tool Color Oracle (www.colororacle. org, Jenny and Kelso 2007), can be helpful tools for testing preliminary colour selections on maps (Figure 14). Depicting value labels on the map face, instead of only in the key, may also assist participants with vision deficiencies.

\section{Key expression and map trust}

The verbal expression "probability" was associated with greater levels of trust than "likelihood". This suggests that verbal expression in the key can play a role in interpretation of hazard map data, as trust is a critical factor in stakeholder engagement with uncertain hazard map data (Frewer and Salter 2007; Wachinger et al. 2013).
For numerical expression, preference of percentages over natural frequencies may reflect a high level of numeracy in the sampled stakeholder group which reported high education levels. While many studies suggest natural frequencies are the most widely- and well-understood numerical expression of probabilistic information (e.g., Hoffrage et al. 2000; Lipkus 2007), others (Reyna and Brainerd 2008; Keller and Siegrist 2009; Severtson and Myers 2013) advise that the effect of expression is dependent on reader numeracy skills. Using a combination of both percentages and natural frequencies on the key was the most favoured option by more than half of participants (Figure 9), and also may be the most inclusive option for reaching trust and understanding among audiences with different numeracy skills. Including natural frequency expressions may also have additional importance in the context of low probability hazard values, as users may be more likely to interpret very low probabilities as "very low hazard" when reading natural frequencies, as opposed to interpreting very low probabilities as "no hazard" when reading percentage values (Kahneman and Tversky 1979; Reyna and Brainerd 1991; Stone et al. 1994). This trend may be indicated by the $\sim 15 \%$ of respondents who viewed the hazard as greater when presented with a natural frequency compared to a percentage. 


\section{Map content and map usefulness}

Overall, participants showed an understanding for the gradational nature of volcanic ash hazard, acknowledging the "realistic" appearance of gradational shading, and dismissing a geopolitical constraint on hazard. These positive indications of understanding of volcanic ash hazard may be due to the high proportion of participants with memories or experiences of volcanoes. Equal preference of fixed ash threshold and fixed probability threshold maps indicates that there are audiences for both types of probabilistic volcanic hazard map content, and that offering different types of outputs is a valuable aspect of probabilistic volcanic hazard analysis tools. Outputs at a number of different threshold levels are likely to be useful, with results of this study suggesting even thresholds as low as $1 \mathrm{~mm}$ of ash can be useful information for many stakeholders. However, many participants drew upon experiences from New Zealand's past minor ashfall events to express the perceived value in information for $1 \mathrm{~mm}$ of ash, and this is likely to be different in other regions, where decision-makers and communities are more frequently exposed to greater thicknesses of volcanic ash.

\section{Map format and the importance of map-maker choices}

The high preference to receive PDF, JPEG, and paper formats (Figure 13), suggest that many hazard map users do not expect to alter any of the properties on the original map (via GIS or other digital tools). Accordingly, the many representation choices for map properties made by the map makers (often volcanic hazard scientists) are important because they are likely to be carried through decisionmaking processes. Participants also expressed intentions to use the maps as tools for communicating with others during decision-making processes, stressing the importance of being able to clearly understand the map themselves in order to be capable of clearly and consistently explaining the hazard map to others, as recommended in a collective communication strategy by key national stakeholders (MCDEM 2010). Considering that maps are likely to be used "as is", it is important that makers of volcanic hazard maps are aware of how choices in map properties can influence communication and understanding.

\section{Methodological remarks}

Semi-structured interviews served as a valuable pilot study methodology for acquiring rich contextual thematic data and for recognising important topics and issues, and the surveys were a valuable method for exploring and testing these topics among a broader sample group. Overall, no major discords or contrasts were recognised between the results of the two methodologies. Inclusion of open-ended text questions in the survey enhanced the richness of the survey data collected and delivered insight into motivations behind key trends. Limitations in the survey methods include possible sampling bias, question order bias, and internet access. The survey was also limited to investigation of the selective map properties and topics addressed in the questions, and other important factors or issues may exist that are not covered here. In snowball sampling, the sample is affected by the network of relationships that exist. Accordingly, more well-connected populations are more likely to be included in the sample (Patton 2002). However, we assume that the proportion of stakeholders $(70 \%)$ to scientists $(30 \%)$ sampled is an appropriate representation of the target population. We found this purposive sampling method was suitable for achieving a high level of participation among those who met the specific criteria related to volcanic hazard maps and decisionmaking, but acknowledge that potential biases could exist within the sample. For example, no statistically significant differences were recognised among age groups for all parameters. However, the $18-24$ and $65+$ year age categories may have been underrepresented for this spread of occupational disciplines (Table 3). Findings may also contrast significantly among groups with a lower rate of tertiary and postgraduate education (Table 3). This study focused on a New Zealand population sample, and important cultural differences may exist for other regions. For example, although red is globally considered a potent, emotional, active colour (Adams and Osgood 1973), it has connotations of danger in many Western cultures, but is a colour of joy in some Eastern ones, and a colour of life in New Zealand Māori culture (e.g., Jackson 1972), and these types of cultural meanings could influence the way users interpret hazard depicted in red colours (Edsall 2007).

Ash fall hazard was investigated in this study because probabilistic hazard analysis approaches are widely available and commonly employed for this type of volcanic hazard (e.g., Scollo et al. 2008; Folch 2012). Other important volcanic hazards, such as lahars (volcanic mudflows) and lava flows are becoming closer to having widely applied probabilistic analysis toolsets, but a probabilistic approach is not yet as common for mapping these gravityand topography- driven volcanic hazards. Some of the results and findings presented here may be different for probabilistic volcanic hazard maps depicting these and other hazards.

\section{Implications for volcanic hazard map design}

Results presented here indicate that stakeholders hold strong views about certain hazard map properties, and highlight the importance of considering user perspectives in hazard map development. Opening the map design process to user contemplation, criticism, and testing in times of volcanic dormancy can help build stronger, more reliable maps and can prevent miscommunications and mistrust during a crisis, when maps are likely to be drafted, disseminated, and duplicated rapidly. The 
quality of visual graphics and maps presented for decisionmaking can play a vital and significant role in the outcomes of a crisis (Tufte 1997). A collaborative and iterative design process which considers diverse user perspectives can help identify key issues, and may help contribute to the development of a more valuable end product.

Our findings suggest that the representation of data classification, colour scheme, key expression, and content, and map presentation format all have an influence on interpretation and communication of probabilistic volcanic hazard map information. These properties have varying influence on map preference, understanding, trust, and application, which could have important effects for hazard management decision-making and incorporation into risk reduction strategies, particularly if a reader relies on intuitive gist or feeling for the information presented to some degree (Reyna and Brainerd 1991; Finucane et al. 2000). Accordingly, while research into user preference is important, as readers are more likely to use a map which appeals to them, complementary empirical measurements of map interpretation are also important because the subjectively preferred map may not always be the most effective map for decisionmaking (Mendonça and Delazari 2011). For example, our results show that although stakeholders preferred the diverging colour scheme (Figure 5C), a diverging colour scheme may convey unintended or false messages of risk (Figure 12C).

Our results also emphasise that there is no one-size-fitsall map presentation. One map cannot comprehensively meet the precise needs of a diverse audience of stakeholders. For example, different ash thresholds may be of concern to different stakeholder groups, and each group may use the map for different modes of communication with different audiences and communities. However, giving a voice to different stakeholder groups in an inclusive approach to hazard mapping can help map makers strive for the most integrative map possible to mediate this issue. Empirical investigation into the interplay of different map properties and how they cumulatively affect the appeal and interpretations of a map with different stakeholder groups can help map makers work towards achieving the most collaborative and effective map possible. A more consentient map can facilitate consistent messaging among stakeholder communities and stakeholder audiences, and reduce the circulation of potentially conflicting information.

Although it is important to communicate a consistent message, it may often be appropriate to create a set of maps instead of a single map, for example, a map set comprising a fixed ash threshold map (Figure 3A) and a fixed probability threshold map (Figure $3 \mathrm{~B}$ ) supplemented with available hazard curves (Figure 4). It is also important to consider that probabilistic volcanic hazard maps are built on the results of a particular input model, which uses a particular set of parameters, assumptions, and limitations. In many circumstances, it may be appropriate to present the results of more than one model. In all cases, explanatory text should be provided on the visual itself to ensure the information is contextually supported.

We further note that the challenges of displaying uncertain information on a map is not unique to volcanic hazards, but has also been discussed in fields such as hurricane hazards (Broad et al. 2007), seismic hazard (Newman et al. 2001), and health hazards (Severtson and Myers 2013). Although the target audiences and messages vary for each discipline, many of these visualisation and communication challenges are analogous or shared, and research undertaken in one field can serve as a valuable resource for guiding enquiries and applications in other hazard-related fields.

\section{Future work}

Few significant differences were recognised between stakeholder and scientist participants in this study, which may be due to limitations in sample size of the study and design of the survey questionnaire (Table 2). Recommendations for future work in this area would be to focus on identifying any key differences affecting hazard map perception among various stakeholder groups (e.g., scientists, emergency managers, and the public). People living in areas potentially exposed to volcanic hazard are very important stakeholders in hazard map information, and are a primary audience for hazard maps in the event of volcanic unrest. However, in many cases, these people are likely to be less familiar with visualisations of volcanic hazard and probabilistic data. As such, future research exploring how volcanic hazard map design influences hazard communication and understanding among these people should be undertaken in order to improve the successful transfer of important hazard information to the wider at-risk community. Further work also needs to be undertaken to identify any further properties which may influence hazard map communication and interpretation, in addition to a more probing investigation of the parameters explored here, such as testing more colour schemes and map content types. We propose that future studies in other volcanic regions or on other natural hazards could adopt a similar methodology to that presented here, and refer the reader to Additional file 1 for a full copy of the online survey.

\section{Conclusion}

It is impossible to achieve a wholly objective representation of complex reality on a map. However, empiricallyinformed representation choices can help probabilistic volcanic hazard maps be designed with an enhanced level of ethical intersubjectivity and transparency which 
may help reduce miscommunication and misunderstanding. There are few existing guidelines available for how to choose appropriate representations of volcanic hazard data on a map, as no previous studies have assessed the impact of such choices on hazard communication. Here, we do not propose a universal standardisation for probabilistic volcanic hazard map properties. We do, however, suggest ten important considerations, in the context of the results of this New Zealand- and volcanic ash-based study, for map makers to take into account when creating maps to be used by stakeholders, such as emergency managers, for high-stakes decisionmaking:

- Using an isarithmic map comprised of gradational shaded stretched data classification with smoothed and labelled $10 \%$ interval probability isopleths can be an effective format for conveying the gradual nature of ashfall hazard and for encouraging critical analysis of the data with a high level of accuracy.

- Red-yellow sequential colour schemes are commonly associated with volcanoes and hazard, and reduce the potential for confusion with hydrological hazard map types. The colour scheme can effectively convey the message that areas depicted as low hazard areas still have some level of hazard present.

- Diverging colour schemes may facilitate unwanted associations with volcanic risk concepts, and may enable use of the map as a reference tool for riskbased response decisions based on the transition area between hues. The colour scheme may convey messages of hazard absence in low hazard areas, and, depending on colour, may also be confused with other hazard map types (e.g., flooding hazard map). However, this scheme may be helpful for facilitating the interpretation of a high hazard "zone".

- Color Brewer (www.colorbrewer2.org, Brewer et al. 2013) is a helpful free online tool for selecting colour blind safe, appropriately balanced map colour schemes. Any colour scheme should be tested using a colour blind filter tool, such as those offered through Color Oracle (Jenny and Kelso 2007) or Adobe Photoshop ${ }^{\circ}$, before dissemination. Including labels of probability on the map face also assists vision deficient users.

- When expressing uncertainty in a dataset, the concept of "confidence" may be grasped more easily and more clearly by stakeholders than lower and upper percentile data ranks, particularly in hazard curve graphics.

- A percent (e.g., 25\%) "probability" is a trusted numerical-verbal expression of probabilistic volcanic hazard, which is considered familiar and reliable.
Including a natural frequency (e.g., 1 in 4) in addition is likely to help to increase understanding of the expression among a broader audience and may reduce the tendency to interpret very low hazard as "no hazard".

- Qualitative hazard descriptors (e.g., "low", "medium", and "high") are less sensitive than numerical hazard values (e.g., 30\%, 45 - 50\%), and may not accurately reflect users' perceived change in hazard probability.

- Both fixed probability and fixed ash threshold maps are valuable probabilistic volcanic hazard map content types for organisational stakeholder groups.

- Static PDF format is a convenient, popular, and preferred format for receiving and sharing volcanic hazard maps, emphasising the importance of map property representation choices.

- Some differences exist in probabilistic volcanic hazard map interpretation between scientists and stakeholders, suggesting that engaging with users in a multi-perspective bottom-up approach to hazard mapping can complement and enhance traditional top-down approaches.

\section{Additional file}

Additional file 1: Copy of the 31-question online survey. The survey was free to access using a one-time-use URL.

\section{Competing interests}

The authors declare that they have no competing interests.

\section{Authors' contributions}

MAT performed the interviews, surveys, analyses, and writing of the manuscript under the guidance and support of JML and JCG. JML and JCG contributed to editing of the manuscript. All authors read and approved the final manuscript.

\section{Acknowledgements}

The authors would like to express thanks and appreciation to the participants of the interviews and surveys. Thanks to E. E. Hudson-Doyle and D.M. Johnston for constructive feedback and discussion, and to S. Jenkins and C. Fearnley for insightful and helpful reviews which improved this manuscript. MAT acknowledges support from the University of Auckland and the DEVORA Project (DEtermining VOlcanic Risk in Auckland) with thanks. JML gratefully acknowledges support from the New Zealand Earthquake Commission.

Received: 30 June 2014 Accepted: 6 January 2015

Published online: 11 February 2015

\section{References}

Adams FM, Osgood CE (1973) A cross-cultural study of the affective meanings of color. J Cross-Cult Psychol 4(2):135-156

American Optometric Association (AOA) (2014) Colour vision deficiency. http://www.aoa.org/patients-and-public/eye-and-vision-problems/glossary-ofeye-and-vision-conditions/color-deficiency?sso=y. Accessed 11 June 2014

Bertin J (1983) Semiology of Graphics (translated by William J. Berg). University of Wisconsin Press, Madison, WI

Blong RJ (1984) Volcanic Hazards: A Sourcebook on the Effects of Eruptions. Academic Press Australia, North Ryde, Australia

Braun V, Clarke V (2006) Using thematic analysis in psychology. Qual Res Psychol 3(2):77-101 
Brewer CA (1994) Color use guidelines for mapping and visualization. In: MacEachren AM, Taylor DRF (eds) Visualization in Modern Cartography. Elsevier, Tarrytown, New York, pp 123-147

Brewer CA (1996) Guidelines for selecting colors for diverging schemes on maps. Cartogr J 33(2):79-86

Brewer CA, Harrower M, Sheesley B, Woodruff A, Heyman D (2013) ColorBrewer 2.0. The Pennyslvania State University, State College, PA, www.colorbrewer2.org

Brewer CA, Pickle L (2002) Evaluation of methods for classifying epidemiological data on choropleth maps in series. Ann Assoc Am Geogr 92(4):662-681

Broad K, Leiserowitz A, Weinkle J, Steketee M (2007) Misinterpretations of the "Cone of Uncertainty" in Florida during the 2004 hurricane season. Bull Am Meteorol Soc 88(5):651-667

Budescu DV, Broomell S, Por H-H (2009) Improving communication of uncertainty in the reports of the intergovernmental panel on climate change. Psychol Sci 20(3):299-308

Calder E, Wagner K, Ogburn S (2012) One hundred and one volcanic hazard maps: what can we learn? In: Abstracts of Cities on Volcanoes 7. IAVCEI, Colima, Mexico, pp 19-23, November 2012

Dent BD, Torguson J, Hodler TW (eds) (2009) Cartography: Thematic Map Design, 6th edn. McGraw-Hill Higher Education, New York

Dieckmann NF, Mauro R, Slovic P (2010) The effects of presenting imprecise probabilities in intelligence forecasts. Risk Anal 30(6):987-1001

Donovan A, Oppenheimer C, Bravo M (2012) The use of belief-based probabilistic methods in volcanology: scientists' views and implications for risk assessments. J Volcanol Geotherm Res 247-248:168-180

Doyle EEH, Johnston DM, McClure J, Paton D (2011) The communication of uncertain scientific advice during natural hazard events. N Z J Psychol 40(4):39-50

Doyle EEH, McClure J, Johnston DM, Paton D (2014) Communicating likelihoods and probabilities in forecasts of volcanic eruptions. J Volcanol Geotherm Res 272:1-15

Edsall R (2007) Cultural factors in digital cartographic design: Implications for communication to diverse users. Cartogr Geogr Inf Sci 34:121-128

Finucane ML, Alhakami A, Slovic P, Johnson SM (2000) The affect heuristic in judgments of risks and benefits. J Behav Decis Mak 13(1):1-17

Folch A (2012) A review of tephra transport and dispersal models; evolution, current status, and future perspectives. J Volcanol Geotherm Res 235-236:96-115

Fournier d'Albe EM (1979) Objectives of volcanic monitoring and prediction. J Geol Soc 136(3):321-326

Fisher A (1991) Risk communication challenges. Risk Anal 11(2):173-179

Frewer L, Salter B (2007) Societal trust in risk analysis: Implications for the interface of risk assessment and risk management. In: Siegrist M, Earle T, Gutscher H (eds) Trust in Cooperative Risk Management: Uncertainty and Scepticism in the Public Mind. Earthscan, London

Harrower M, Brewer CA (2003) ColorBrewer.org: An online tool for selecting colour schemes for maps. Cartogr J 40(1):27-37

Haynes K, Barclay J, Pidgeon N (2007) Volcanic hazard communication using maps: an evaluation of their effectiveness. Bull Volcanol 70(2):123-138

Hoffrage U, Lindsey S, Hertwig R, Gigerenzer G (2000) Communicating statistical information. Science 290(5500):2261-2262

Jackson M (1972) Aspects of symbolism and composition in Maori art. Bijdragen tot de Taal-, Land- en Volkenkunde 128(1):33-80

Jenny B, Kelso NV (2007) Color design for the color vision impaired. Cartographic Perspectives 57:61-67

Kahneman D, Tversky A (1979) Prospect theory: an analysis of decision under risk. Econometrica 47:263-291

Keller C, Siegrist M (2009) Effect of risk communication formats on risk perception depending on numeracy. Med Decis Making 29:483-490

Kunz M, Hurni L (2011) How to enhance cartographic visualisations of natural hazards assessment results. Cartogr J 48(1):60-71

Leonard GS, Stewart C, Wilson TM, Procter JN, Scott BJ, Keys HJ, Jolly GE, Wardman JB, Cronin SJ, McBride SK (2014) Integrating multidisciplinary science, modelling and impact data into evolving, syn-event volcanic hazard mapping and communication: A case study from the 2012 Tongariro eruption crisis, New Zealand. J Volcanol Geotherm Res 286:208-232

Lipkus IM (2007) Numeric, verbal, and visual formats of conveying health risks: suggested best practices and future recommendations. Med Decis Making 27(5):696-713

MacEachren AM (1992) Visualizing uncertain information. Cartographic Perspective 13:10-19

MacEachren AM (1995) How Maps Work. The Guilford Press, New York
Mader HM, Coles SG, Connor CB, Connor LJ (eds) (2006) Statistics in Volcanology, vol 1. Special Publications of IAVCEI. Geological Society, London

Marzocchi W, Newhall C, Woo G (2012) The scientific management of volcanic crises. J Volcanol Geotherm Res 247-248:181-189

MCDEM (2002) Civil Defence Emergency Management Act 2002 (CDEM Act). Ministry of Civil Defence \& Emergency Management, New Zealand, Public Act 2002 No. 33

MCDEM (2010) Working from the same page: consistent messages for CDEM. Ministry of Civil Defence \& Emergency Management, Wellington, New Zealand

Mendonça A, Delazari L (2011) What do People prefer and what is more effective for maps: a decision making test. In: Ruas A (ed) Advances in Cartography and GIScience. Volume 1. Lecture Notes in Geoinformation and Cartography. Springer, Berlin Heidelberg

Monmonier M (1996) How to Lie with Maps. The University of Chicago Press, Chicago

Morgan DL (2007) Paradigms lost and pragmatism regained: methodological implications of combining qualitative and quantitative methods. J Mixed Methods Res 1(1):48-76

Nairn IA, Self S, Cole JW, Leonard GS, Scutter C (2001) Distribution, stratigraphy, and history of proximal deposits from the C. AD 1305Kaharoa eruptive episode at Tarawera Volcano, New Zealand. N Z J Geol Geophys 44:467-484

Nave R, Isaia R, Vilardo G, Barclay J (2010) Re-assessing volcanic hazard maps for improving volcanic risk communication: application to Stromboli Island, Italy. J Maps 2010:260-269

Newhall CG, Hoblitt RP (2002) Constructing event trees for volcanic crises. Bull Volcanol 64:3-20

Newman A, Schneider J, Stein S, Mendez A (2001) Uncertainties in seismic hazard maps for the New Madrid Seismic Zone and implications for seismic hazard communication. Seismol Res Lett 72(6):647-663

Olson JM, Brewer CA (1997) An evaluation of color selections to accommodate map users with color-vision impairments. Ann Assoc Am Geogr 87(1):103-134

Patton MQ (ed) (2002) Qualitative Research and Evaluation Methods, 3rd edn Sage Publications, Thousand Oaks, CA

Reyna VF, Brainerd CJ (1991) Fuzzy-trace theory and framing effects in choice: Gist extraction, truncation, and conversion. J Behav Decis Mak 4(4):249-262

Reyna VF, Brainerd CJ (2008) Numeracy, ratio bias, and denominator neglect in judgments of risk and probability. Learn Individ Differ 18(1):89-107

Robinson AH (1967) Psychological aspects of color in cartography. International Yearbook of Cartography 7:50-59

Robinson AH, Morrison JL, Muehrcke PC, Jon Kimerling A, Guptill SC (1995) Elements of Cartography, 6th edn. John Wiley \& Sons, Inc, New York

Scollo S, Folch A, Costa A (2008) A parametric and comparative study of different tephra fallout models. J Vol Geother Res 176:199-211

Scott BJ, Potter SH (2014) Aspects of historical eruptive activity and volcanic unrest at Mt. Tongariro, New Zealand: 1846-2013. J Volcanol Geotherm Res 286:263-276

Severtson DJ, Myers JD (2013) The influence of uncertain map features on risk beliefs and perceived ambiguity for maps of modeled cancer risk from air pollution. Risk Anal 33(5):818-837

Severtson DJ, Vatovec C (2012) The theory-based influence of map features on risk beliefs: Self-reports of what is seen and understood for maps depicting an environmental health hazard. J Health Commun 17:836-856

Slocum TA (1999) Thematic Cartography and Visualization. Prentice Hall, Upper Saddle, NJ

Spiegelhalter D, Pearson M, Short I (2011) Visualizing uncertainty about the future. Science 333(6048):1393-1400

Stone ER, Yates JF, Parker AM (1994) Risk communication: absolute versus relative expressions of low-probability risks. Organ Behav Hum Decis Process 60(3):387-408

Thompson MA, Lindsay JM, Sandri L, Biass S, Bonadonna C, Jolly G, Marzocchi W. (under review) Exploring the influence of vent location and eruption style on tephra fall hazard from the Okataina Volcanic Centre, New Zealand.

Tonini R, Sandri L, Thompson MA (in press) PyBetVH: a Python tool for probabilistic volcanic hazard assessment and for generation of Bayesian hazard curves and maps, Computers and Geosciences.

Tufte ER (1997) Visual and statistical thinking: displays of evidence for making decisions. In: Visual Explanations: images and Quantities, Evidence and Narrative. Graphics Press, Chesire, Connecticut

UNISDR (2009) UNISDR Terminology on Disaster Risk Reduction. United Nations International Strategy for Disaster Reduction (UNISDR), Geneva, Switzerland 
Wachinger G, Renn O, Begg C, Kuhlicke C (2013) The risk perception paradoxImplications for governance and communication of natural hazards. Risk Anal 33(6):1049-1065

Walker GPL, Self S, Wilson L (1984) Tarawera 1886, New Zealand - A basaltic phinian fissure eruption. J Volcanol Geotherm Res 21:61-78

Wolfe JM, Horowitz TS (2004) What attributes guide the deployment of visual attention and how do they do it? Nat Rev Neurosci 5:495-501

Woo G (2008) Probabilistic criteria for volcano evacuation decisions. Nat Hazards 45:87-97

Woo G (2009) A New Era of Volcano Risk Management. Risk Management Solutions, Inc, Newark, CA

Submit your manuscript to a SpringerOpen ${ }^{\odot}$ journal and benefit from:

- Convenient online submission

- Rigorous peer review

- Immediate publication on acceptance

- Open access: articles freely available online

- High visibility within the field

- Retaining the copyright to your article

Submit your next manuscript at $>$ springeropen.com 